\title{
Impacts of the Indian Ocean Dipole on Sea Level and Gyre Circulation of the Western Tropical Pacific Ocean
}

\author{
JiNG DUAN AND YUANLONG Li \\ CAS Key Laboratory of Ocean Circulation and Waves, Institute of Oceanology, Chinese Academy of Sciences, and Function \\ Laboratory for Ocean Dynamics and Climate, Qingdao National Laboratory for Marine Science and Technology, and Center \\ for Ocean Mega-Science, Chinese Academy of Sciences, Qingdao, China
}

LEI ZHANG

Department of Atmospheric and Oceanic Sciences, University of Colorado Boulder, Boulder, Colorado

FAN WANG

CAS Key Laboratory of Ocean Circulation and Waves, Institute of Oceanology, Chinese Academy of Sciences, and Function Laboratory for Ocean Dynamics and Climate, Qingdao National Laboratory for Marine Science and Technology, and Center for Ocean Mega-Science, Chinese Academy of Sciences, Qingdao, China

(Manuscript received 21 October 2019, in final form 13 February 2020)

\begin{abstract}
Interannual variabilities of sea level and upper-ocean gyre circulation of the western tropical Pacific Ocean (WTPO) have been predominantly attributed to El Niño-Southern Oscillation (ENSO). The results of the present study put forward important modulation effects by the Indian Ocean dipole (IOD) mode. The observed sea level in the WTPO shows significant instantaneous and lagged correlations (around -0.60 and 0.40 , respectively) with the IOD mode index (DMI). A composite of 14 "independent" IOD events for 1958-2017 shows negative sea level anomalies (SLAs) of 4-7 cm in the WTPO during positive IOD events and positive SLAs of $6-8 \mathrm{~cm}$ in the following year that are opposite in sign to the El Niño effect. The IOD impacts are reproduced by large-ensemble simulations of a climate model that generate respectively 430 and 519 positive and negative independent IOD events. A positive IOD induces westerly winds over the western and central tropical Pacific and causes negative SLAs through Ekman upwelling, and it facilitates the establishment of a La Niña condition in the following year that involves enhanced Pacific trade winds and causes positive SLAs in the WTPO. Ocean model experiments confirm that the IOD affects the WTPO sea level mainly through modulating the tropical Pacific winds. Variability of the Indonesian Throughflow (ITF) induced by IOD winds has a relatively weak effect on the WTPO. The IOD's impacts on the major upper-ocean currents are also considerable, causing anomalies of $1-4 \mathrm{~Sv}\left(1 \mathrm{~Sv} \equiv 10^{6} \mathrm{~m}^{3} \mathrm{~s}^{-1}\right)$ in the South Equatorial Current (SEC) and North Equatorial Countercurrent (NECC) volume transports.
\end{abstract}

\section{Introduction}

Sea level variability is closely associated with ocean dynamical processes and has profound socioeconomic impacts on low-lying islands and coastal zones (e.g., Stammer et al. 2013; Han et al. 2017). Understanding sea level variability on various time scales is critical for future

Supplemental information related to this paper is available at the Journals Online website: https://doi.org/10.1175/JCLI-D-190782.s1.

Corresponding author: Yuanlong Li, liyuanlong@qdio.ac.cn prediction and adaptation strategies. The western tropical Pacific Ocean (WTPO) is among the regions exhibiting strongest sea level variabilities on interannual, decadal, and multidecadal time scales (e.g., Han et al. 2014; Hu et al. 2015; Merrifield 2011; Qiu and Joyce 1992; Qiu and Chen 2012). In this region, sea level also tends to covary with the upper-ocean circulation on these time scales, characteristic of the first-mode baroclinic response to the tropical Pacific wind forcing (e.g., Meyers 1979; Kessler 1990; Qiu and Lukas 1996; Qiu and Chen 2010) associated with natural climate modes such as El Niño-Southern Oscillation (ENSO) (Cazenave and Remy 2011; Han et al. 2017; Meng et al. 2019; Merrifield 2011). 
ENSO has been suggested to be the primary source of interannual sea level variability in the tropical Pacific. Large-scale sea level falling in the WTPO and rising in the east were observed during El Niño condition, as a result of the mass redistribution by the relaxed trade winds over the tropical Pacific (Jin 1997; Merrifield et al. 1999; Nerem et al. 2010; Zhang and Church 2012). Strong El Niño events such as 1982/83 and 1997/98 caused low sea level extremes in the WTPO that exposed shallow reefs, causing damages to local ecosystems (Widlansky et al. 2014). Sea level variability is not an isolated phenomenon but tightly linked to the variations of the upper-ocean circulation through geostrophy. As the major component of the WTPO circulation system, the South and North Equatorial Currents (SEC and NEC) and the North Equatorial Countercurrent (NECC) tend to be dramatically enhanced in total volume transport during El Niño events (e.g., Kessler and Taft 1987; Qiu and Lukas 1996; Johnston and Merrifield 2000; Kashino et al. 2009; Qiu and Chen 2012; Hsin and Qiu 2012; Zhao et al. 2013; Zhai and Hu 2013; Zhang et al. 2017). Changes of these ocean currents are essential for the time-varying heat budget of the western Pacific warm pool and redistribution of oceanic properties, including sea surface temperature (SST) over the tropical Indo-Pacific Ocean (Jin 1997; Picaut 1997; Clement et al. 2005; Hu et al. 2015). Intensive research efforts have been devoted to answer the question as to how ENSO affects the WTPO sea level and gyre circulation. Interannual anomalies of sea level and upperocean circulation in the WTPO can be by and large explained by the linear accumulation of wind forcing signature of ENSO over the Pacific basin in the form of first-mode baroclinic Rossby waves (e.g., Qiu and Joyce 1992; Qiu and Lukas 1996; Zhao et al. 2013; Hsin and Qiu 2012; Zhai and $\mathrm{Hu} 2013$ ).

Complementing the classic dynamic framework described above, there are also other processes potentially modulating the WTPO sea level and circulation. The correlations between ocean currents in the far western Pacific and ENSO are, in fact, not high (e.g., Lukas 1988; Qiu and Chen 2010; Zhao et al. 2013; Duan et al. 2019a). Nonlinearity of the western boundary currents (Yuan et al. 2018a), higher baroclinic modes (Kim et al. 2004; Ren et al. 2018), equatorial wind forcing (Duan et al. 2019a), and eddy-current interaction (Qiu et al. 2015) have been proposed to strongly affect the WTPO circulation. Yet none of them has been successfully utilized to reconcile the inconsistency between the WTPO interannual anomaly and ENSO. Recently we have begun to realize the vital role played by interbasin climate interaction in regulating variability behaviors of the ocean and atmosphere [see Cai et al. (2019) and Wang (2019) for updated reviews]. The WTPO neighbors the Indian Ocean with connections through the Indonesian Throughflow (ITF) in the ocean and the Walker circulation in the atmosphere. Existing studies have suggested that the climate anomalies in the tropical Indian Ocean may exert modulation effects on low-level winds of the WTPO (e.g., Annamalai et al. 2005; Kug et al. 2006; Yang et al. 2007; Xie et al. 2009; Izumo et al. 2010; Dayan et al. 2015).

The Indian Ocean dipole (IOD) mode initiates in boreal summer and peaks in fall (e.g., Saji et al. 1999; Cai and Qiu 2013). A positive IOD (pIOD) event is characterized by SST cooling near the coast of Sumatra and warming in the western Indian Ocean [vice versa for negative IOD (nIOD) events]. Different from the Indian Ocean basin (IOB) mode, which is largely the Indian Ocean's response to ENSO (Klein et al. 1999; Alexander and Scott 2002; Lau and Nath 2003; Shinoda et al. 2004; Schott et al. 2009; Du et al. 2009; Xie et al. 2009), some IOD events develop independently from ENSO, although an El Niño (a La Niña) condition in the Pacific generally favors the occurrence of pIOD (nIOD) events (e.g., Annamalai et al. 2003; Izumo et al. 2010, 2016).

The IOD has been proposed to affect zonal winds in the western Pacific in the following spring and influence ENSO phase transition (Izumo et al. 2014, 2010, 2016; Dayan et al. 2015), although some studies argued that the net effect of the IOD might be small owing to a cancellation in effect between the warm and cold poles (Annamalai et al. 2005; Ohba and Ueda 2007). The warm eastern pole of an nIOD can produce easterly wind anomalies in the WTPO and vanishes after fall. The abrupt termination of nIOD causes rapid growth of westerly wind anomalies in the WTPO in the subsequent spring, damping the existing La Niña signatures and promoting a rapid phase transition to El Niño. Similarly, the cold eastern pole of a pIOD can produce westerly wind anomalies in the WTPO. After the mature phase of pIOD, easterly wind anomalies in the WTPO can emerge accompanied by the abrupt demise of pIOD, tending to damp the existing El Niño and favoring the rapid phase transition to La Niña (Izumo et al. 2014, 2010). The evident influence from the IOD on the following year's ENSO event is seen in most state-of-theart climate models (Jourdain et al. 2016).

In addition to atmospheric teleconnection, the IOD can also affect the Pacific through the oceanic channel effect of the Indonesian Throughflow (Yuan et al. 2011, 2013). Yuan et al. (2011) pointed out that the IODinduced upwelling anomalies can propagate through the Indonesian Seas as Kelvin waves and influence the next year's ENSO event. The relationship between the IOD and ENSO through the ITF was indicated by 
observations (Yuan et al. 2018b, 2013) and model simulations (e.g., Santoso et al. 2011; Hu et al. 2019). There were also several previous studies suggesting a limited influence of the ITF based on the fact that only a very small portion of the IOD-induced Kelvin wave signals can enter the Pacific, and most of them are reflected back to the Indian Ocean (Clarke 1991; Schwarzkopf and Böning 2011).

Given the impacts of the IOD on Pacific winds and the ITF and its partial independence from ENSO, the IOD can be regarded as an external source of variability for the WTPO. It is imperative to clarify the IOD's impacts on sea level anomalies (SLAs) and circulation variability of the WTPO and the roles played by atmospheric and oceanic processes in the IOD-WTPO teleconnection. The present study attempts to identify and quantify the impacts of "independent" IOD events by analyzing data of observation, ocean reanalysis, and climate model simulations and compare with ENSO-induced variability. We also explore the processes through which the IOD causes SLAs and gyre circulation variations using experiments of a reduced-gravity ocean (RGO) model. These efforts may improve our understanding of the interannual variability of the WTPO and complement to our knowledge of the interbasin climate interactions. The rest of the paper is structured as follows. Section 2 describes the data and methodology. Section 3 evaluates the impacts of so-called independent IOD events on SLAs in the WTPO. Section 4 explores the atmospheric and oceanic processes through which the IOD induces SLAs and circulation variations. Section 5 summarizes the primary findings of the paper.

\section{Data and methods}

\section{a. Datasets and definitions}

To obtain interannual variability of sea level in the WTPO, monthly sea level data from the $0.25^{\circ}$ Archiving Validation, and Interpretation of Satellite Oceanography (AVISO) (Le Traon et al. 1998) product for 1993-2017 and the $1^{\circ}$ European Centre for Medium-Range Weather Forecasts (ECMWF) Ocean Reanalysis System 4 (ORAS4) (Balmaseda et al. 2013) product for 1958-2017 are analyzed. The reason for choosing ORA-S4 is that it assimilates along-track altimeter sea level anomalies (Balmaseda et al. 2013) and thus relatively reliable. Also, ORA-S4 can realistically simulate the multiple time scale variabilities of SLA at six tidal stations (Fig. S1 in the online supplemental material), indicating a good representation of ORA-S4, even before the satellite era. We also analyze the Cross-Calibrated Multi-Platform (CCMP) wind data for 1993-2017 (Atlas et al. 2011) and ECMWF wind data for 1958-2017 to examine the relevant variability in surface wind fields. The CCMP wind data are based on satellite, buoy, and model wind data using a variational analysis method, with a $0.25^{\circ}$ horizontal resolution. The ECMWF wind data are used to force the ocean model of ORA-S4 and consist of the 2.5 40-yr ECMWF Re-Analysis (ERA-40; Uppala et al. 2005) for 1958-88, the $0.75^{\circ}$ ECMWF interim reanalysis (ERA-Interim; Dee et al. 2011) for 1989-2009, and ECMWF operational analysis from 2010 onward (Balmaseda et al. 2013).

The IOD mode index (DMI) and Niño-3.4 index are calculated for the period of 1958-2017 using Hadley Centre Sea Ice and Sea Surface Temperature (HadISST) data (Rayner 2003) of the Met Office. Following Saji et al. (1999), the DMI is defined as the SST anomaly difference between the western $\left(10^{\circ} \mathrm{S}-10^{\circ} \mathrm{N}, 50^{\circ}-70^{\circ} \mathrm{E}\right)$ and eastern $\left(10^{\circ} \mathrm{S}-0^{\circ}, 90^{\circ}-110^{\circ} \mathrm{E}\right)$ tropical Indian Ocean during September-November (SON). The Niño-3.4 index is the SST anomaly averaged over Niño-3.4 region $\left(5^{\circ} \mathrm{S}-5^{\circ} \mathrm{N}, 170^{\circ}-120^{\circ} \mathrm{W}\right)$ from December to February of the next year. The IOD and ENSO years defined as those falling out of the one standard deviation (STD) range, which are $0.36^{\circ}$ and $0.93^{\circ} \mathrm{C}$ for DMI and Niño-3.4, respectively. Among others, the independent pIOD (nIOD) events are defined as those occurring in the absence of El Niño (La Niña). Similarly, the independent El Niño (La Niña) events refer to those occurring in the absence of pIOD (nIOD) events. A concurrent positive (negative) IOD-ENSO event is defined as a case with a pIOD and an El Niño (an nIOD and a La Niña) co-occurring. We track the evolution of each event from the occurring year [year(0)] to the following year [year(1)]. Note that concurrent pIOD-La Niña and nIOD-El Niño events hardly happened during the period of 1958-2017 and are not discussed in this study.

\section{b. CESM large-ensemble simulation}

The independent IOD events selected from observational and reanalysis data are rather few due to the short records, preventing us from performing robust statistical analysis. To overcome this drawback and obtain more samples, we also utilize Large-Ensemble (LE) simulations of the National Center for Atmospheric Research (NCAR) Community Earth System Model (CESM) (Kay et al. 2015). By using the same model configurations (CESM version 1 with $\sim 1^{\circ}$ resolution in the atmosphere, ocean, land, and sea ice components; Hurrell et al. 2013) and the same external forcing, CESM-LE simulations are of 40 members, with each representing a unique climate trajectory arising from a small disturbance in initialization. Monthly sea level and wind data of the historical simulations from 1920 to 2005 (Lamarque et al. 2010) of CESM-LE are used for our analysis. The 
CESM-LE provides $40 \times 86=3440$ years of data, greatly increasing the sample size of independent IOD and ENSO events. These events are generated within the same dynamical framework and suitable for our comparative analysis.

\section{c. Reduced-gravity ocean model}

To explore the wind forcing effects on interannual variability of sea level and circulation in the WTPO, a 1.5-layer nonlinear RGO model is employed. This model is configured to the Indian and Pacific Oceans over $20^{\circ} \mathrm{E}-70^{\circ} \mathrm{W}, 45^{\circ} \mathrm{S}-40^{\circ} \mathrm{N}$ with horizontal resolutions of $0.25^{\circ} \times 0.25^{\circ}$. This model is able to simulate the ocean's first baroclinic mode response to surface wind forcing that is the dominant form of interannual variability in sea level and upper-ocean circulation of the WTPO. For the equations and parameterizations of the model, readers are referred to $\mathrm{Chen}$ and $\mathrm{Wu}$ (2015). In addition to sea level, we also quantify the impacts of the IOD on major currents of the WTPO circulation, including the NEC, the NECC, the northern branch of South Equatorial Current (herein SEC-N), the South Equatorial Countercurrent (SECC), and the NEC's bifurcation latitude (NBL). The volume transport of the NEC in the RGO model is computed along $145^{\circ} \mathrm{E}$ as

$$
T_{\mathrm{NEC}}=-\int_{8^{\circ} \mathrm{N}}^{18^{\circ} \mathrm{N}} u(h+H) d y,
$$

where $h$ is the upper-layer thickness (ULT) anomaly, $H=350 \mathrm{~m}$ is the initial ULT, and $u$ is the upper-layer zonal velocity. Similarly, the volume transport of the NECC is computed by integrating $u(h+H)$ at $145^{\circ} \mathrm{E}$ from $2^{\circ}$ to $7^{\circ} \mathrm{N}$, and the transports of the SEC-N and SECC are calculated by integrating $u(h+H)$ at $170^{\circ} \mathrm{E}$ between $5^{\circ} \mathrm{S}-2^{\circ} \mathrm{N}$ and $12^{\circ}-6^{\circ} \mathrm{S}$, respectively. The ITF volume transport is defined as the integration of $v(h+H)$ at $5^{\circ} \mathrm{S}$ between $110^{\circ}$ and $130^{\circ} \mathrm{E}$ ( $\mathrm{Li}$ et al. 2017):

$$
T_{\mathrm{ITF}}=-\int_{110^{\circ} \mathrm{E}}^{130^{\circ} \mathrm{E}} v(h+H) d x
$$

where $v$ is the upper-layer meridional velocity. The NBL is defined as the latitude where the upper-layer meridional transport within $2^{\circ}$ band off the Philippine coast equals zero (Chen and Wu 2011, 2012; Qiu and Lukas 1996; Zhao et al. 2012; Duan et al. 2019b). The Ekman pumping velocity $(\mathrm{EPV})$ is calculated as $w_{E}=\operatorname{curl}(\tau / f) \rho^{-1}$, where $\tau$ is the wind stress vector, $f$ is the Coriolis parameter, and $\rho=1025 \mathrm{~kg} \mathrm{~m}^{-3}$ is seawater density.

For all the data and model results mentioned above, the monthly climatology and the linear trend are removed to obtain anomalies. To highlight interannual variability, an 8-yr high-pass filter is applied to anomaly fields to remove the influence of decadal changes. Using a filter window of 5-7 years does not dramatically affect the results. Estimation of statistical significance is based on a two-tailed Student's $t$ test with the effective degree of freedom estimated as $n / 1.5$ following Xie et al. (2009), where $n$ is the data length in years.

\section{Impacts of the IOD on the WTPO}

\section{a. Analysis based on observational data}

SLAs in the WTPO are significantly correlated with both ENSO and IOD, based on ORA-S4 data of 19582017 and AVISO data of 1993-2017 (Fig. 1). The distribution of correlation coefficients with IOD is broadly similar to that with ENSO, with negative correlations in the Indo-Pacific warm pool and positive values in other regions, probably reflecting the evident covariance between ENSO and IOD (e.g., Annamalai et al. 2003, 2005; Kug et al. 2006; Izumo et al. 2010).

Since both IOD and ENSO are tightly phase-locked to the seasonal cycle, we examine the relationships of monthly SLAs in the WTPO with the SeptemberNovember (SON) DMI and the December-February (DJF) Niño-3.4 over year(0) and year(1). The lead-lag correlations are computed for SLAs of two representative regions with coherent significant negative correlations (Fig. 2), that is, the northwestern tropical Pacific Ocean (NWPO; $127^{\circ}-155^{\circ} \mathrm{E}, 5^{\circ}-15^{\circ} \mathrm{N}$ ) and the western equatorial Pacific Ocean (WEPO; $135^{\circ}-165^{\circ} \mathrm{E}, 5^{\circ} \mathrm{S}-$ $5^{\circ} \mathrm{N}$ ). Results based on both ORA-S4 and AVISO show that SLAs have significant correlations with both ENSO and IOD during June(0)-February(1), during which ENSO and IOD events are roughly in their mature stage (Fig. 2). The maximum correlations with the IOD are around -0.6 , lower than those with ENSO $(-0.9)$. One major difference lies in that while ENSO tends to induce SLAs of the same sign during its developing and decaying years, SLAs associated with the IOD are opposite in year(0) and year(1). Note that SLAs of July(1)-December(1) show higher correlations with the IOD $(+0.4)$ than those with ENSO (from +0.2 to +0.3 ), although these correlations are marginally or not significant. Correlations at a 1-yr lag indicate possible persistent impacts of IOD events on the WTPO, which requires in-depth investigation.

Some IOD events can occur independently without ENSO influence and are suitable for the investigation of the IOD impacts (e.g., Izumo et al. 2010, 2016; Yuan et al. 2011). We find 14 independent IOD events during the period of 1958-2017, including 6 independent 
(a) Corr. ORA-S4 SLAs and DMI

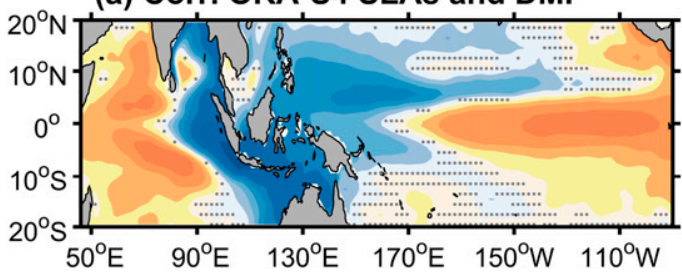

(b) Corr. ORA-S4 SLAs and Nino-3.4

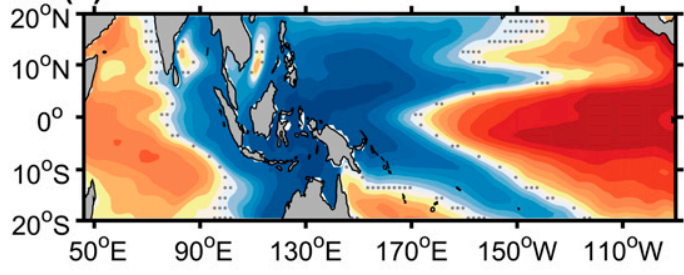

(c) Corr. AVISO SLAs and DMI

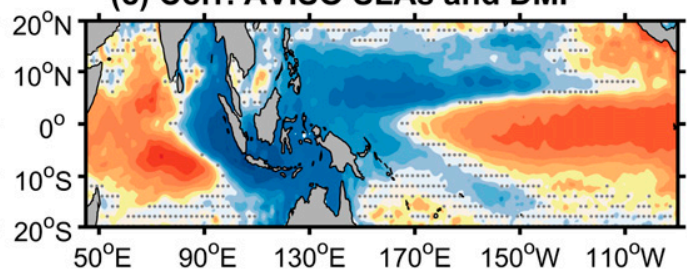

(d) Corr. AVISO SLAs and Nino-3.4

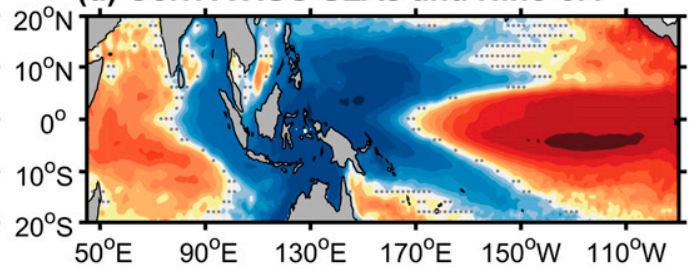

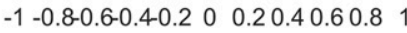

FIG. 1. (a) Correlation coefficients between interannual sea level anomalies (SLAs) derived from ORA-S4 and the SON Indian Ocean dipole mode index (DMI) derived from HadISST from 1958 to 2017. (b) As in (a), but for DJF Niño-3.4 derived from HadISST. (c),(d) As in (a) and (b), but between the SLAs derived from AVISO and SON DMI and DJF Niño-3.4 derived from HadISST from 1993 to 2017. Stippled regions indicate the fields below the $95 \%$ confidence level, based on a two-tailed Student's $t$ test. Note that DJF denotes the successive 3 months from December to February of the next year.

pIODs $(1961,1963,1967,1987,1994$, and 2006) and 8 independent nIODs (1958, 1960, 1964, 1968, 1974, 1992, 1996, and 2016) (Fig. 3). Among them, strong SLAs in both the NWPO (Fig. 3a) and the WEPO (Fig. 3b) were seen in several of the events (e.g., 1961 and 1987 for pIODs and 1964, 1996, and 2016 for nIODs). Strong positive SLAs tend to occur in nIOD years (1996 and 2016 in the NWPO; 1958, 1964, 1968, 1974,1996 , and 2016 in the WEPO), but there are also positive SLAs seen in pIOD (1961 and 1994 in the NWPO; 1967 in the WEPO), which are against the overall negative IOD-WTPO correlation. Such inconsistency indicates the complexity of the problem, given the strong asymmetry and event-by-event variability of the IOD. Weak El Niño and La Niña conditions may also affect the relationship between the IOD and WTPO. Note that negative SLAs in 1987 are the strongest of all six independent pIOD events, which may also be affected by the 1986/87 El Niño event (Chen and Li 2018). Another interesting phenomenon is the biennial oscillatory behaviors of the IOD, with the pIOD events of 1963, 1967, and 1994 followed by nIOD events. During the period of 19582017, we also detect four independent El Niño events (1965, 1976, 1986, and 2009), eight independent La Niña events $(1970,1973,1984,1988,1995,1999,2007$,
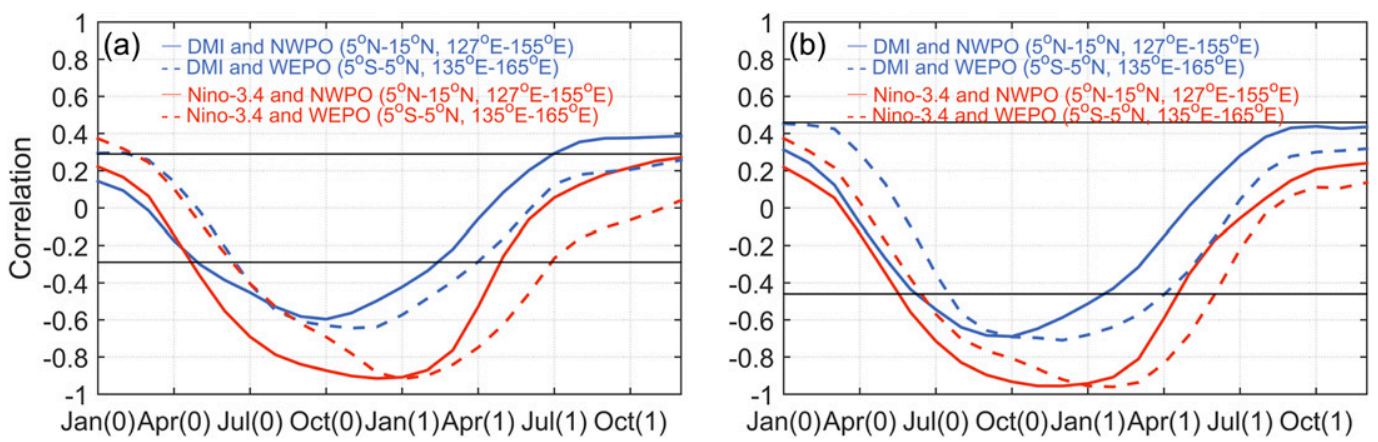

FIG. 2. (a) Correlation coefficients between SLAs averaged in the northwestern Pacific Ocean (NWPO; $127^{\circ}-$ $155^{\circ} \mathrm{E}, 5^{\circ}-15^{\circ} \mathrm{N}$ ) and the western equatorial Pacific Ocean (WEPO; $135^{\circ}-165^{\circ} \mathrm{E}, 5^{\circ} \mathrm{S}-5^{\circ} \mathrm{N}$ ) derived from ORA-S4 and SON DMI and DJF Niño-3.4 derived from HadISST for the period of 1958-2017. (b) As in (a), but SLAs are derived from AVISO of 1993-2017. Two black lines in each panel indicate the $95 \%$ confidence level based on a twotailed Student's $t$ test. 


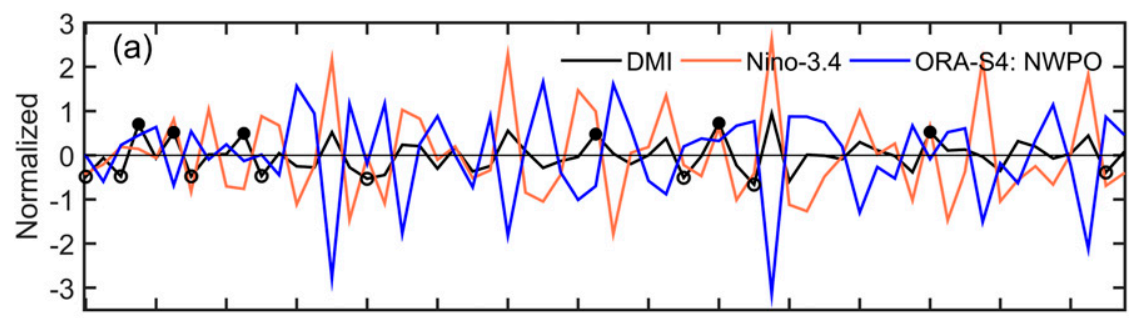

195819621966197019741978198219861990199419982002200620102014

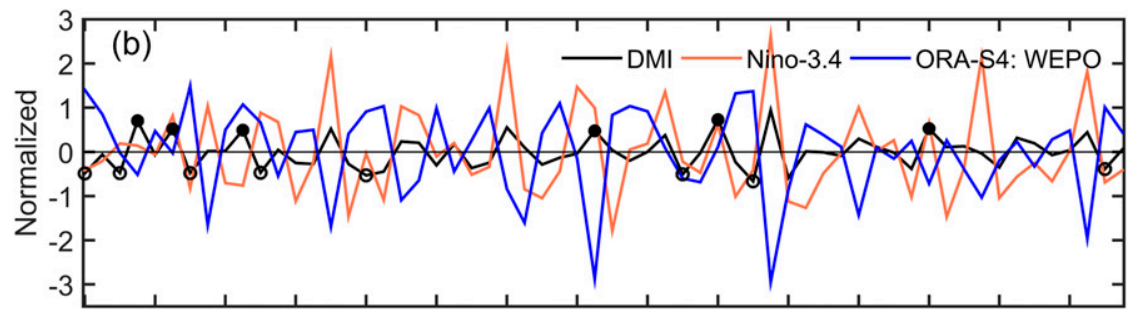

195819621966197019741978198219861990199419982002200620102014

FIG. 3. (a) SON DMI, DJF Niño-3.4, and JJASON SLA in the NWPO from 1958 to 2017. (b) As in (a), but for the WEPO SLA. DMI and Niño-3.4 are derived from HadISST, and the NWPO and the WEPO SLAs are derived from ORA-S4. Each variable is normalized by its standard deviation. The standard deviations for the DMI, Niño-3.4, NWPO SLA, and WEPO SLA are $0.36^{\circ} \mathrm{C}, 0.93^{\circ} \mathrm{C}, 7.01 \mathrm{~cm}$, and $4.67 \mathrm{~cm}$, respectively. Black dots denote independent positive IOD ( $\mathrm{pIOD}$ ) years, and circles denote independent negative IOD (nIOD) years.

and 2010), five concurrent pIOD-El Niño events (1972, 1982, 1991, 1997, and 2015), and three concurrent nIODLa Niña events $(1975,1998$, and 2005), where the year(0) is used to define each event.

Although subjected to large uncertainties, the composite of 14 independent IOD events may, to some degree, represent the overall impacts of IOD on the WTPO. In Fig. 4, we show the composites of 14 independent IOD events, 12 independent ENSO events, and 8 concurrent IOD-ENSO events in a positive-minusnegative fashion. Composite maps of both AVISO and

(a) ORA-S4 NWPO

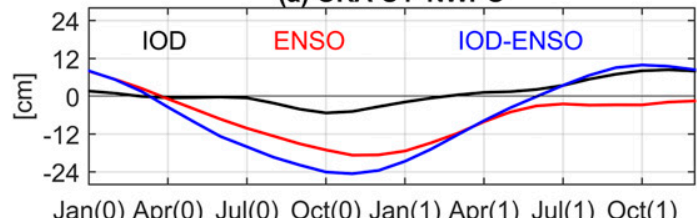

(b) ORA-S4 WEPO

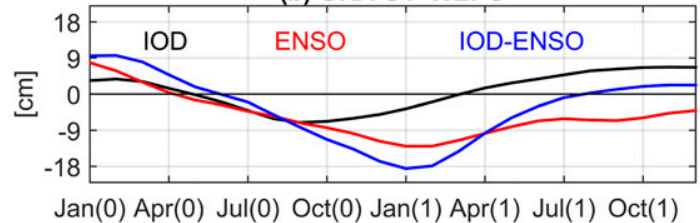

ORA-S4 SLAs are broadly consistent with the correlation shown in Fig. 2. An independent pIOD event can likely induce negative SLAs in the WTPO from July(0) to February(1), with amplitudes being smaller than the negative SLAs caused by independent El Niño events. The concurrent IOD-ENSO causes stronger SLAs than either ENSO or IOD alone. This may indicate an enhancement effect on SLAs by the IOD or else reflect the fact that concurrent events are usually the strongest events such as the 1982, 1997, and 2015 cases (e.g., Luo et al. 2010; Izumo et al. 2010). The positive SLAs in the

(c) AVISO NWPO

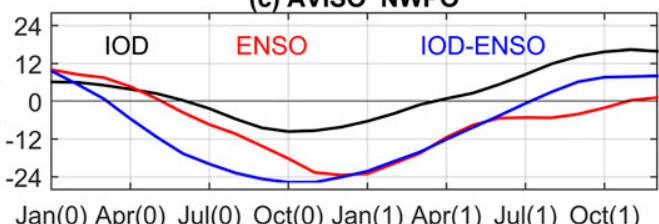

(d) AVISO WEPO

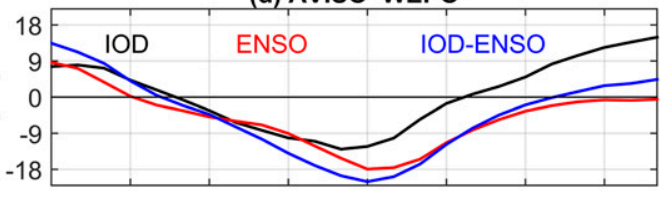

$\operatorname{Jan}(0) \operatorname{Apr}(0) \operatorname{Jul}(0) \operatorname{Oct}(0) \operatorname{Jan}(1) \operatorname{Apr}(1) \operatorname{Jul}(1) \operatorname{Oct}(1)$

FIG. 4. Positive minus negative composites of SLAs averaged in the (a) NWPO and (b) WEPO derived from ORA-S4 from January(0) to December(1) for independent IOD events, independent ENSO events, and concurrent IOD-ENSO events during 1958-2017 based on HadISST. (c),(d) As in (a) and (b), but for SLAs of the NWPO and the WEPO derived from AVISO during 1993-2017. 
(a) Independent IOD

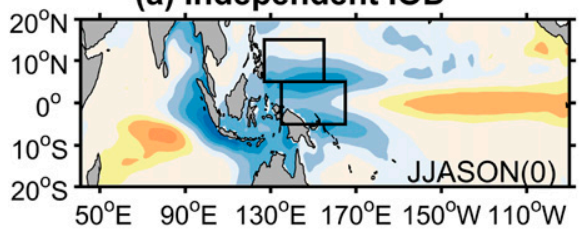

(b) Independent IOD

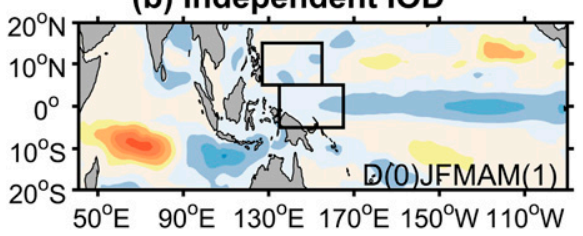

(c) Independent IOD

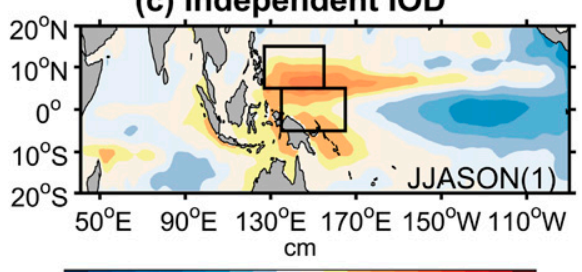

(d) Independent ENSO

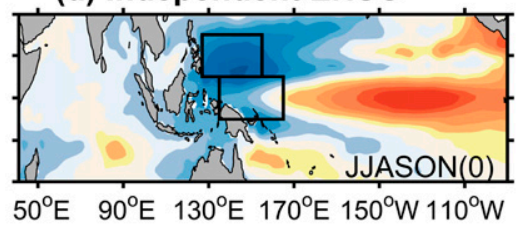

(e) Independent ENSO

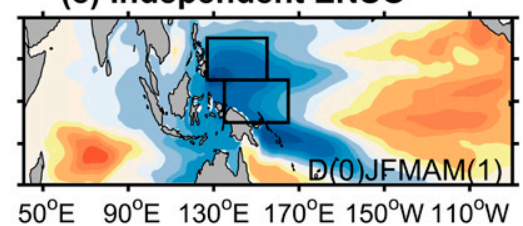

(f) Independent ENSO

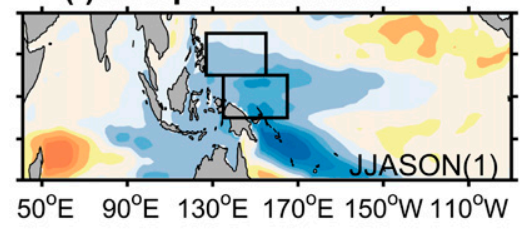

(g) IOD-ENSO

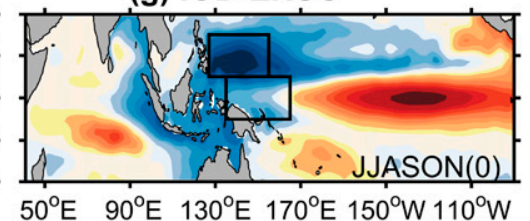

(h) IOD-ENSO

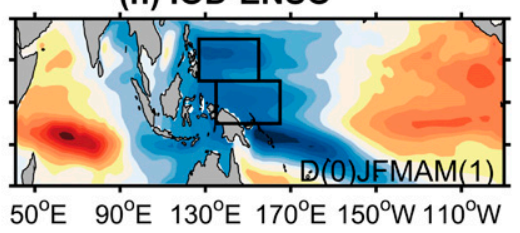

(i) IOD-ENSO

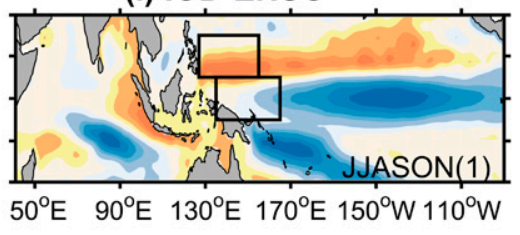

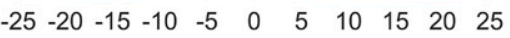

FIG. 5. Positive minus negative composite maps of SLAs $(\mathrm{cm})$ derived from ORA-S4 for independent IOD events during (a) JJASON(0), (b) D(0)JFMAM(1), and (c) JJASON(1) for 1958-2017. (d)-(f) As in (a)-(c), but for independent ENSO events. (g)-(i) As in (a)-(c), but for concurrent IOD-ENSO events. Two black boxes denote the NWPO and the WEPO.

IOD composite from April(1) to December(1) are opposite in sign to those in ENSO composite, likely indicating a considerable lagged effect of IOD. More interestingly, concurrent IOD-ENSO events also tend to cause positive SLAs in the latter half of year(1) that are opposite to ENSO-alone signatures. It is possible that the lagged effects of IOD in the following year are stronger than ENSO in year(1), as indicated by Fig. 2.

Quantified with ORA-S4 data, the composite IOD produces an average negative SLA of $-6.61 \mathrm{~cm}$ in the WEPO in SON(0), which accounts for $78.2 \%$ and $59.6 \%$ of SLAs of the ENSO composite and concurrent IOD-ENSO composite, respectively. In the NWPO, the negative SLA of $-4.73 \mathrm{~cm}$ in the IOD composite is much weaker than the other two composites $(27.9 \%$ and $20.1 \%$ ). However, in SON(1), the positive SLAs of +6.53 and $+7.84 \mathrm{~cm}$ of the IOD composite are evidently larger than those of the ENSO composite. These results indicate that independently occurring IOD events may exert strong impacts on the WTPO sea level that differ from ENSO signatures, and this impact is stronger in the WEPO. Considering the small Coriolis parameter $f$ near the equator, the large SLAs in the WEPO region indicate strong anomalies of the upper-ocean geostrophic circulation.

Spatial patterns of SLAs and wind fields are also examined for three periods (Figs. 5 and 6). During
June-November of year(0), negative SLAs emerge in the tropical western Pacific in the IOD composite (Fig. 5a). SLAs of ENSO and IOD-ENSO composites, in comparison, show slightly different spatial distributions and larger amplitudes. Particularly, in the WTPO the strong negative SLAs can cover the entire Philippine Sea south of $20^{\circ} \mathrm{N}$ (Figs. $5 \mathrm{~d}, \mathrm{~g}$ ), whereas those in the IOD composite are confined within $10^{\circ}$ of the equator. The resemblance between ENSO and IOD-ENSO composites suggests the domination of ENSO effect in this stage, albeit with considerable IOD effect. Note that SLA patterns of the IOD and ENSO are different from their corresponding SST anomaly patterns. Prominent positive SLAs associated with the mature phase of the pIOD are seen only in the Seychelles-Chagos thermocline ridge region but not prevailing in the western tropical Indian Ocean as SST warming (Saji et al. 1999). Negative SLAs in the WTPO correspond to the westerly wind anomalies and positive (upward) off-equatorial EPV $\left(w_{E}\right)$ anomalies in the tropical Pacific west of $\sim 150^{\circ} \mathrm{W}$ (Figs. 6a,d,g), which drive upwelling Rossby waves (e.g., Qiu and Lukas 1996; Qiu and Chen 2010; Li et al. 2012; Duan et al. 2019a). Note that anomalous westerlies in Fig. 6a are linked to SST cooling near the coast of Sumatra, which causes a divergence of surface winds, and not to the SST warming in the eastern 
(a) Independent IOD

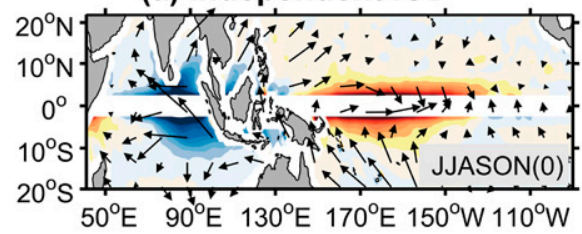

(b) Independent IOD

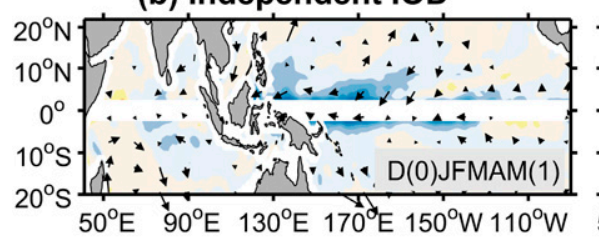

(c) Independent IOD (d) Independent ENSO

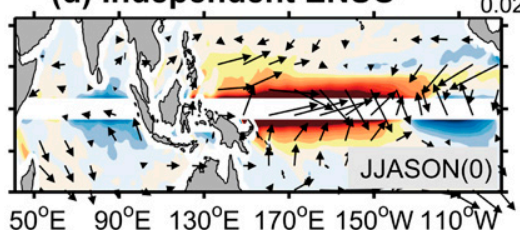

(e) Independent ENSO

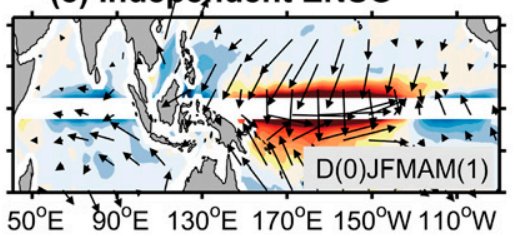

(f) Independent ENSO

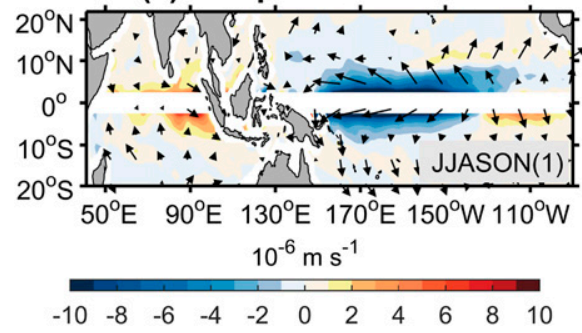

$\overrightarrow{0.02 \mathrm{~Pa}}$

(g) IOD-ENSO

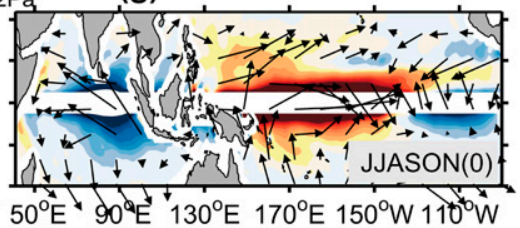

(h) IOD,ENSO

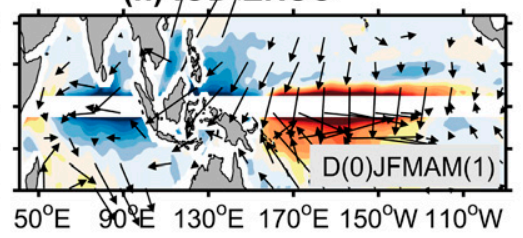

(i) IOD-ENSO

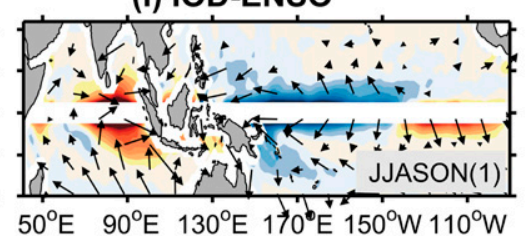

$\begin{array}{lllllllllll}-10 & -8 & -6 & -4 & -2 & 0 & 2 & 4 & 6 & 8 & 10\end{array}$

FIG. 6. Positive minus negative composite maps of wind stress (vectors; Pa) and Ekman pumping velocity $w_{E}\left(\right.$ color shading; $10^{-6} \mathrm{~m} \mathrm{~s}^{-1}$; not computed for $2^{\circ} \mathrm{S}-2^{\circ} \mathrm{N}$ ) derived from ECMWF for independent IOD events during (a) JJASON(0), (b) D(0)JFMAM(1), and (c) JJASON(1) for 1958-2017. (d)-(f) As in (a)-(c), but for independent ENSO events. (g)-(i) As in (a)-(c), but for concurrent IOD-ENSO events.

Pacific as in Figs. 6d and 6g (see Fig. 9c of Luo et al. 2010 or Figs. 12a and 12d). This is supported by the fact that strong easterly winds are found in the eastern Pacific in Figs. 6d and 6g but not in Fig. 6a. Surface wind anomalies of concurrent events are the strongest in both the Indian and Pacific Oceans.

After the mature phase of IOD, the negative SLAs in the WTPO quickly decays (Fig. 5b), featuring the quick termination of IOD events (Izumo et al. 2010), whereas by sharp contrast the negative SLAs of the ENSO and IOD-ENSO composites persist through winter to spring (Figs. 5e,h) owing to the sustained westerly wind anomalies over the equatorial Pacific (Figs. 6e,h). By June-November [JJASON(1)], the composite of independent IOD events shows positive SLAs in the WTPO and also near the Sumatra coast (Fig. 5c) corresponding to anomalous easterlies (or enhanced Pacific trade winds) over the tropical Pacific and negative $w_{E}$ anomalies off the equator (Fig. 6c). These variations suggest that a La Niña condition has been established over the Pacific Ocean. Previous studies have reported the role of a pIOD in favoring the development of a La Niña condition in the following year (e.g., Annamalai et al. 2005; Kug and Kang 2006; Izumo et al. 2010; Dayan et al. 2015). The positive SLAs in the WTPO may be intimately associated with the newly developed La Niña, which will be discussed with more details in section 3 b. SLAs and wind anomalies in the tropical Indian Ocean are weaker than those in the tropical Pacific Ocean, suggesting that the sea level rise in the WTPO is not directly caused by the tropical Indian Ocean forcing. By contrast, independent ENSO events leave negative SLAs in the WTPO (Fig. 5f), characterizing the slow decay of the El Niño without IOD effect with westerlies and positive $w_{E}$ persisting in the tropical Pacific (Fig. 6f). Moreover, SLAs of the concurrent IODENSO events show more similarities to those of IOD events, particularly the positive SLAs in the NWPO and negative SLAs in the central and eastern equatorial Pacific (Fig. 5i). The concurrent events also show easterly winds in the tropical Pacific (Fig. 6i), consistent with Fig. $6 c$ but weaker in amplitude. The composite SLAs and surface winds of the concurrent IOD-ENSO events during JJASON(1) (Figs. 5i and 6i) are roughly the sum of the IOD and ENSO composites, and the lagged effect of a pIOD is likely stronger than that of an El Niño in determining the SLAs and surface wind anomalies over the tropical Pacific. The composite maps derived from AVISO and CCMP agree with those of ORA-S4 and ECMWF, albeit with some detailed differences (Figs. S2 and S3), probably resulting from 
different data lengths or validity of the reanalysis data. To verify the reliability of the composite results, partial correlation and multiple linear regression analyses are further made between SLAs and either the DMI or the Niño-3.4 index. The results are broadly consistent with those of composite analysis (Figs. S4-S7). Therefore, in the following, we mainly use composite analysis to examine the IOD effect.

\section{b. Analysis based on CESM-LE simulations}

Analysis of observational and reanalysis data presented above suggests that IOD events may exert a considerable effect on sea level variability of the WTPO in the absence of ENSO effect. These results are however subjected to large uncertainties due to the small sample size and event-by-event variability. One can argue that the ENSO effect still exists in the so-called independent IOD events, and its signatures may strongly contaminate the IOD composite. To isolate the IOD impacts in a clean manner, we utilize CESM-LE simulations that provide many more sample events for further analysis. We first validate the performance of the 1920-2005 historical simulations of CESM-LE in representing the IOD and ENSO modes. Power spectra of DMI and Niño-3.4 derived from 40 members of CESMLE simulations agree well with those derived from HadISST of 1920-2005 (Fig. S8) in not only amplitude but also typical frequency. In addition, correlation coefficients between DMI and Niño-3.4 in HadISST and CESM-LE during 1920-2005 are calculated. Ensemble mean correlation coefficient between DMI and Niño-3.4 for the peak IOD season of September-November based on CESM-LE 40 members is 0.55 (with the maximum of 0.68 and the minimum of 0.42 ), which is broadly consistent with those of HadISST (0.62) and previous studies (e.g., Saji and Yamagata 2003; Yamagata et al. 2004). These comparisons suggest a good performance of CESM-LE in simulating the IOD and ENSO modes.

Using the same criteria as described in section 2, we identify 430 independent pIOD events and 519 independent nIOD events in the 3440 years of CESM-LE results. The large sample size allows us to tackle the weak ENSO events that fail to meet the one STD criterion but still could affect the independent IOD events. We examine the distribution of DJF Niño-3.4 in pIOD and nIOD years. The histogram suggests an evident asymmetry, with much more positive Niño-3.4 values for pIODs and more negative Niño-3.4 values for nIODs (gray bars in Figs. 7a and 7b). This indicates that the composite for pIOD (nIOD) events has been contaminated by the effect of the weak El Niño (La Niña) state. To exclude this effect, we randomly discard the pIOD and nIOD events with positive and negative Niño-3.4 values respectively, using a bootstrap method (Austin and Tu 2004) until the histogram reaches symmetry (black dot lines in Figs. 7a and 7b). As such, the average Niño-3.4 value of all events is close to zero, and the ENSO effect is supposed to be excluded. After this procedure, there are 308 and 229 independent pIOD and nIOD events left for the composite analysis, respectively.

We compared the composite of these pIOD events with those affected by weak El Niño and La Niña events (events with Niño-3.4 $>0$ and Niño-3.4 $<0$ in Fig. 7a) in Fig. S9. The differences in SLAs among the three groups of events, particularly those in JJASON(0), confirm the influence of weak ENSO events. There are however coherent features among the three. The negative SLAs in the WEPO in JJASON(0) and the positive SLAs in JJASON(1) exist in all three groups and also seen in observational data (Fig. 5). These anomalies are likely robust IOD signatures that are insensitive to the contamination of the concurrent weak ENSO-like conditions. Checking the Niño-3.4 value in the subsequent year, we found that most of the pIOD events are followed by a La Niña condition (Fig. 7c). This tendency is also obvious in observational data (Fig. 7d). Among the six independent pIOD events in HadISST data, four are followed by obvious La Niña conditions, and only one of them is followed by an El Niño condition. There is no evident tendency for nIOD events to be followed by El Niño events in observation.

Since the number of independent IOD events is much larger now, the composites are separately computed for pIOD and nIOD events. As shown in Fig. 8, the composite SLAs for independent pIOD events in the NWPO and the WEPO are broadly consistent with those of AVISO and ORA-S4. In SON(0), the composite pIOD shows a weak negative SLA of $-1.33 \mathrm{~cm}$ in the WEPO, accounting for $63.3 \%$ and $20.4 \%$ of those of the El Niño and concurrent pIOD-El Niño composites, respectively. SLAs in the NWPO are even smaller. These SLAs are weaker than those seen in ORA-S4 composites (Fig. 4). It is likely that the IOD composite based on ORA-S4 data still contains the effects of weak El Niño events, which also cause negative SLAs in the WTPO, and these effects have been largely removed from the composite of CESMLE. In SON(1), the composite pIOD induces a positive SLA of $+1.99 \mathrm{~cm}$ in the WEPO and meanwhile a large positive SLA of $+4.82 \mathrm{~cm}$ in the NWPO that is 4 times larger than the negative SLA caused by the composite El Niño. Composites of concurrent pIODEl Niño events are strongly affected by the pIOD, showing dramatically different anomalies from the El Niño composite. Composites of nIOD, La Niña, and 
(a) pIOD (LE)

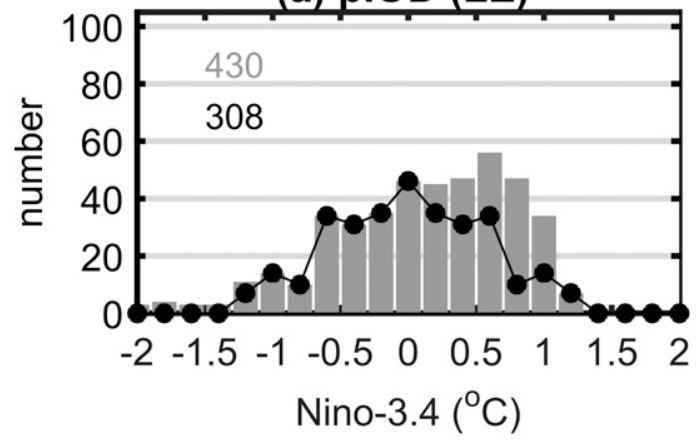

(c) post-pIOD (LE)

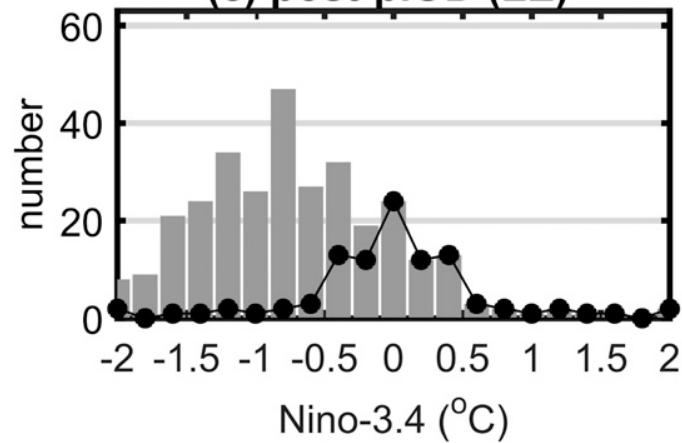

(b) nIOD (LE)

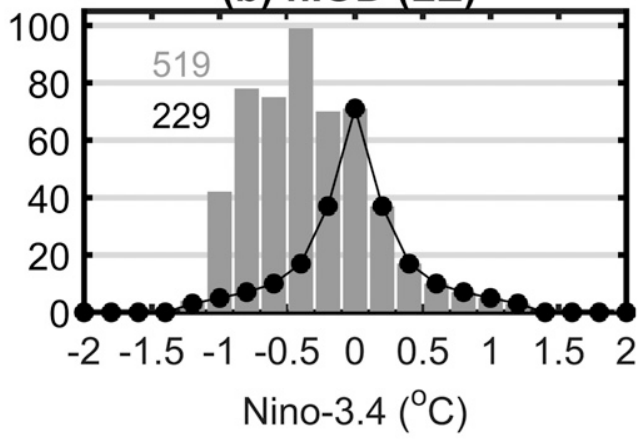

(d) post-IOD (HadISST)

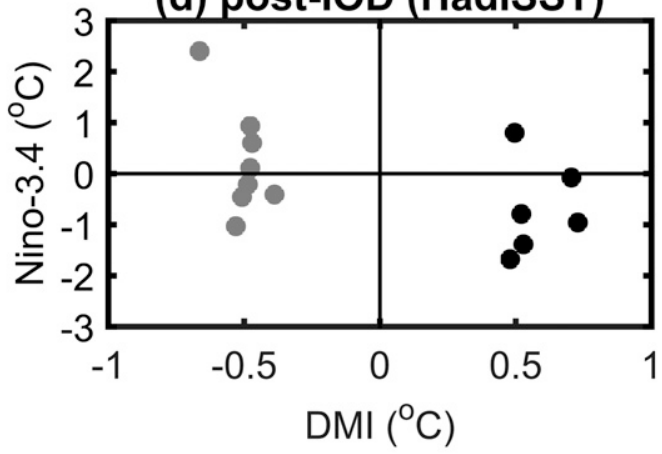

FIG. 7. (a) Histogram of DJF Niño-3.4 (gray bars) derived from CESM Large-Ensemble (CESM-LE) simulations for the years of independent pIOD events. The black dot line denotes the symmetric version of gray bars. (b), (c) As in (a), but for the years of independent nIOD events and the years after the independent pIOD events, respectively. Black and gray numbers in (a) and (b) denote the total number of gray bars and black dot lines. (d) Scatterplots of SON DMI vs DJF Niño-3.4 for independent IOD events derived from HadISST during 1958-2017. The pIOD and nIOD events are plotted in black and gray dots, respectively.

concurrent nIOD-La Niña events are approximately the opposite to those of positive composites (Fig. S10).

The spatial patterns of SLAs derived from CESMLE are as shown in Fig. 9. The IOD composite for JJASON(0) (Fig. 9a) is broadly similar to those of ORA-S4 (Fig. 5a) and AVISO (Fig. S2a), except that SLAs in the WTPO are weaker in amplitude and more confined to the equator (between $10^{\circ} \mathrm{S}$ and $5^{\circ} \mathrm{N}$ ). Composites of El Niño and concurrent pIOD-El Niño events are consistent with those derived from observation. The negative SLAs in the WTPO in the IOD composite can be largely explained by westerly winds and positive $w_{E}$ in the western and central tropical Pacific (Fig. 10a). Composite anomalies of surface winds here are roughly weaker than those based on ECMWF and CCMP, again implying the effect of weak ENSO on selected independent IOD events in section 3a. During the period of December-May [D(0)JFMAM(1)], negative SLAs occupy the Pacific equator, and the positive SLAs emerge in the NWPO (Fig. 9b), as the response to the easterly winds and negative $w_{E}$ over the tropical Pacific (Fig. 10b) that implies a developing La Niña.
Composites for JJASON(1) are also consistent with those derived in section $3 \mathrm{a}$. The pIOD causes prevailing sea level rise in the WTPO with the largest anomalies occurring in the NWPO (Fig. 9c). Anomalies induced by concurrent events (Fig. 9i) are approximately the sum of the pIOD and El Niño signatures, showing positive SLAs in the NWPO that is caused by the pIOD (Fig. 9c) and negative SLAs in the WEPO left by the El Niño (Fig. 9f). Again, these SLAs can be largely explained by surface wind forcing over the tropical Pacific Ocean (Figs. 10c,f,i). During JJASON(1), strong easterlies (or enhanced trade winds) are established in the tropical Pacific with negative off-equatorial $w_{E}$ featuring a $\mathrm{La}$ Niña condition (recall Fig. 7c), which acts to generate positive SLAs in the WTPO. Note that the positive SLAs near Sumatra in Fig. 9c and prevailing westerly winds along the Indian Ocean equator in Fig. 10c characterize an nIOD condition of the tropical Indian Ocean, which is more evident than maps based on observational data. Therefore, the pIOD tends to induce an nIOD accompanied by a La Niña in the following year, and the resultant La Niña may be the primary 
(a) NWPO

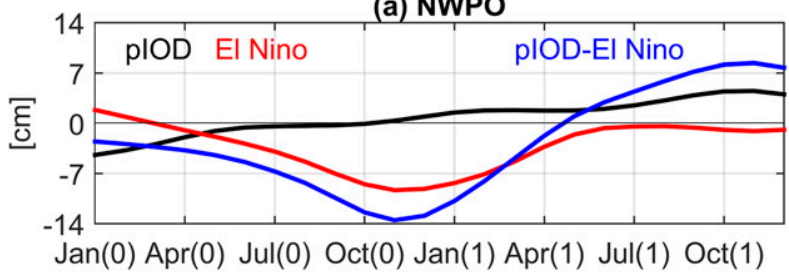

(b) WEPO

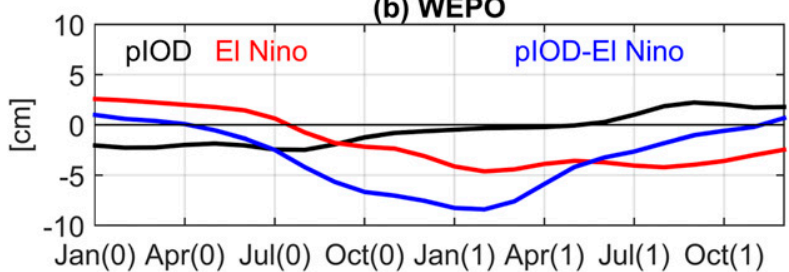

FIG. 8. Composite SLAs averaged in the (a) NWPO and (b) WEPO derived from CESM-LE simulations for independent pIOD events, independent El Niño events, and concurrent pIODEl Niño events.

cause for the strong sea level rise in the WTPO and the positive WTPO-IOD correlation with a lag of $\sim 1$ year (Fig. 2). The La Niña can also develop after the concurrent event (Figs. 9i and 10i) primarily as the result of the pIOD rather than the El Niño, given that an independent El Niño tends to decay slowly and leave westerly wind anomalies in the following year (Figs. 10e,f). The cases of negative events are nearly opposite to the positive ones (Figs. S11 and S12). In summary, the analysis of CESM-LE supports the conclusion that the IOD can exert considerable impacts on the WTPO sea level and surface winds over the tropical Pacific, and this effect is particularly prominent in the subsequent year.

Time-longitude plots of SLAs and zonal wind stress $\tau_{x}$ anomalies averaged over the latitudinal bands of the NWPO $\left(5^{\circ}-15^{\circ} \mathrm{N}\right)$ and the WEPO $\left(5^{\circ} \mathrm{S}-5^{\circ} \mathrm{N}\right)$ are shown in Fig. 11 to track oceanic wave signals and wind forcing throughout year(0) to year(1). The negative SLAs in the WTPO in year(0) are likely caused by anomalous westerlies (positive $\tau_{x}$ ). This is particularly true for $\mathrm{El}$ Niño and concurrent events during which westerly winds are strong in year(0). Subsequent to the pIOD, the westerly winds in the WTPO are replaced by easterly winds, likely contributing to the generation of positive SLAs in JJASON(1). There are no evident wave propagation signals detected in the pIOD composites, different from the composites for El Niño and concurrent events. This implies that SLAs in the IOD composite are largely attributed to local processes in the WTPO, such as local wind forcing and the ITF variability, and their importance will be assessed in section 4 .

The contrasting characteristics between IOD and ENSO in phase transition are of particular interest. Subsequent to the pIOD event, a cold SST anomaly is left near the date line (Fig. 12a), which partly originated (a) Independent pIOD

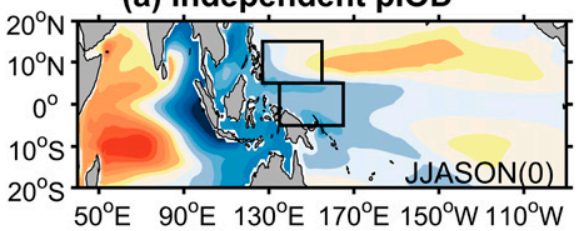

(b) Independent pIOD

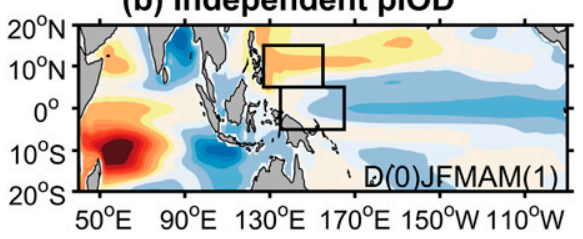

(c) Independent pIOD

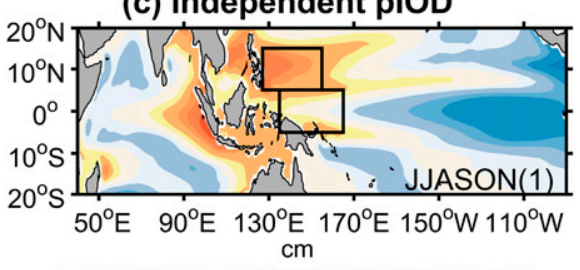

(d) Independent El Nino

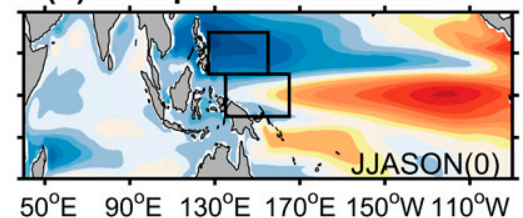

(e) Independent EI Nino

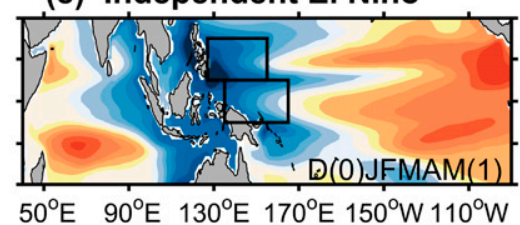

(f) Independent EI Nino

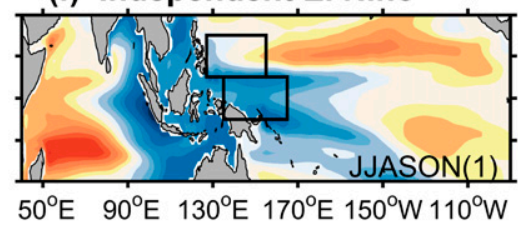

(g) pIOD-EI Nino

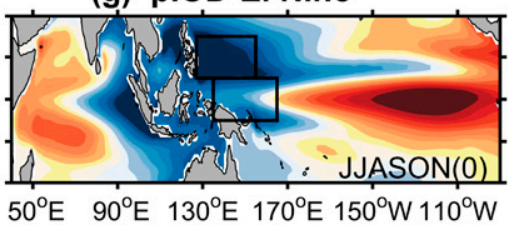

(h) pIOD-EI Nino

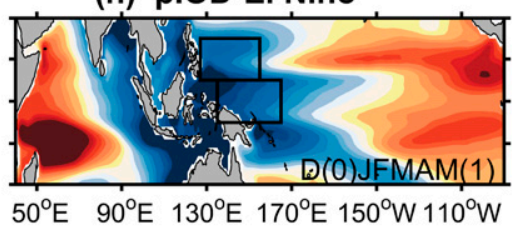

(i) pIOD-EI Nino

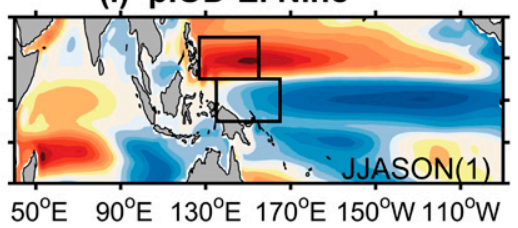

$\begin{array}{lllllllllll}-10 & -8 & -6 & -4 & -2 & 0 & 2 & 4 & 6 & 8 & 10\end{array}$

FIG. 9. Composite maps of SLAs (cm) derived from CESM-LE simulations for independent pIOD events during (a) JJASON(0), (b) D(0)JFMAM(1), and (c) JJASON(1). (d)-(f) As in (a)-(c), but for independent El Niño events. (g)-(i) As in (a)-(c), but for concurrent pIOD-El Niño events. 
(a) Independent pIOD

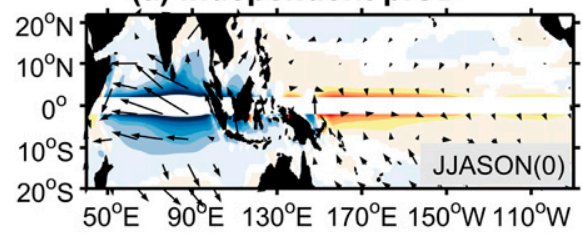

(b) Independent pIOD

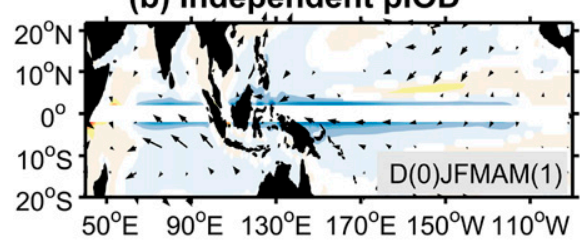

(c) Independent pIOD

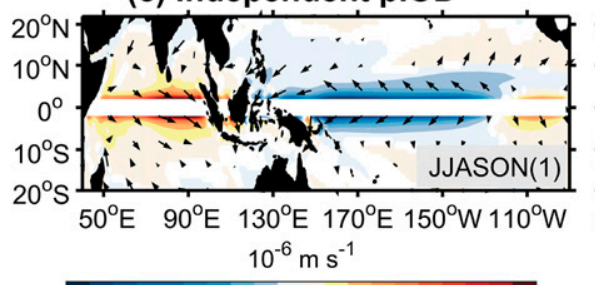

$\begin{array}{lllllllllll}-10 & -8 & -6 & -4 & -2 & 0 & 2 & 4 & 6 & 8 & 10\end{array}$ (d) Independent EI Nino

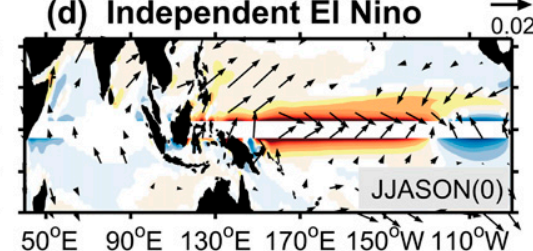

(e) Independent EI Nino

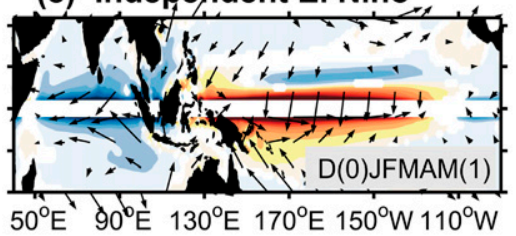

(f) Independent EI Nino

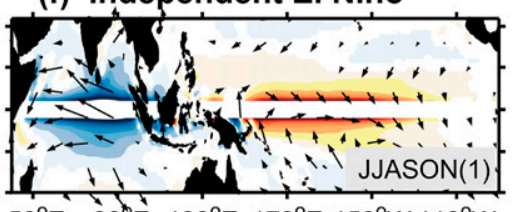

$50^{\circ} \mathrm{E} 90^{\circ} \mathrm{E} 130^{\circ} \mathrm{E} 170^{\circ} \mathrm{E} 150^{\circ} \mathrm{W} 110^{\circ} \mathrm{W}$

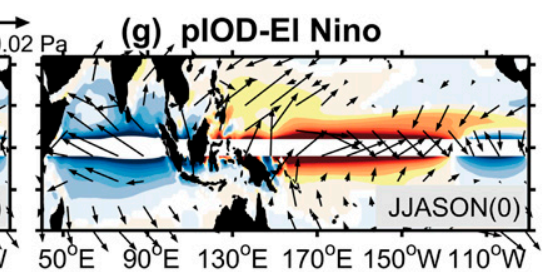

(h) plob-EI Nino

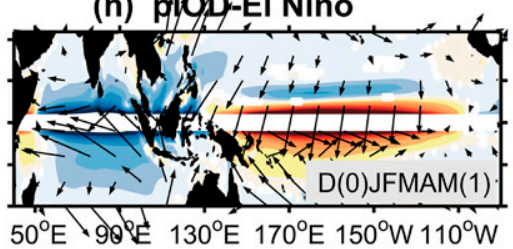

(i) pIOD-EI Nino

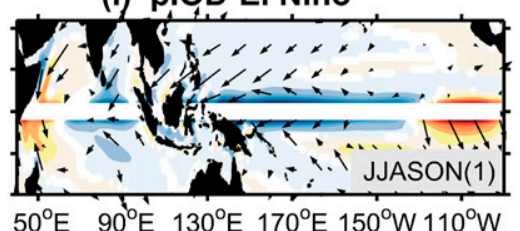

FIG. 10. Composite maps of wind stress (vectors; Pa) and Ekman pumping velocity $w_{E}$ (color shading; $10^{-6} \mathrm{~m} \mathrm{~s}^{-1}$; not computed for $2^{\circ} \mathrm{S}-$ $2^{\circ} \mathrm{N}$ ) derived from CESM-LE simulations for independent pIOD events during (a) JJASON(0), (b) D(0)JFMAM(1), and (c) JJASON(1). (d)-(f) As in (a)-(c), but for independent El Niño events. (g)-(i) As in (a)-(c), but for concurrent pIOD-El Niño events. All the plotted composite zonal wind stress $\tau_{x}$ and $w_{E}$ exceed the $95 \%$ confidence level from a two-tailed Student's $t$ test.

from the WEPO in the form of eastward-propagating equatorial Kelvin waves and partly is forced by the growing easterly winds near the equator (Fig. 11d). The Bjerknes feedback between the SST cooling and easterly winds prompts the growth of the coupled anomalies gradually to a La Niña event (Figs. 12b,c). The basinwide SST warming over the Indian Ocean in spring (Fig. 12b) favors the development of the La Niña by driving easterly wind anomalies in the eastern Indian Ocean and WTPO (Fig. 10b). Regarding the generation of this weak basinwide warming, one possibility is that it results from the quickly decaying pIOD. Whether and how a pIOD leads to the subsequent basinwide warming needs to be explored in the future. Another possibility is that ENSO effects still exist in this composite and cause this basinwide warming in the Indian Ocean. The El Niño event, on the other hand, causes a stronger SST warming in the Indian Ocean (Klein et al. 1999; Alexander et al. 2002; Du et al. 2009), but the existing westerly winds and SST warming over the tropical Pacific are likely too strong to be reversed by the remote forcing from the Indian Ocean.

\section{Atmospheric and oceanic processes}

The analysis above confirms the IOD impacts on the WTPO sea level, which are likely through modulating surface wind variability in the western-central Pacific Ocean. However, the Indian Ocean affects the Pacific through both the atmospheric bridge (e.g., Izumo et al. 2010, 2014) and ocean channel effect of the ITF (e.g., Yuan et al. 2011, 2013). It is necessary to gain further insights into the specific processes through which IOD events cause SLAs in the WTPO. Using the 1.5-layer RGO model described in section $2 \mathrm{c}$, we can further assess the relative importance of the atmospheric and oceanic processes.

We first examine the performance of the RGO model in representing variations of the WTPO sea level and the ITF. Two simulations forced by ECMWF winds for 1958-2017 and CCMP winds for 1993-2017 are performed, named the ECMWF-RGO run and CCMP-RGO run, respectively. As shown in Figs. 13a and 13b, upper-layer thickness anomalies (ULTAs) derived from ECMWF-RGO and CCMP-RGO are consistent with SLAs from ORA-S4 and AVISO for the NWPO and the WEPO regions. The correlation coefficients between ECMWF-RGO and ORA-S4 are 0.9 and 0.91 for the NWPO and the WEPO, and the correlations between CCMP-RGO and AVISO are 0.87 and 0.88 , respectively. The evolution of ULTAs in the WTPO in the IOD composite derived from RGO results are broadly consistent with the composite SLAs 
(a) Independent pIOD

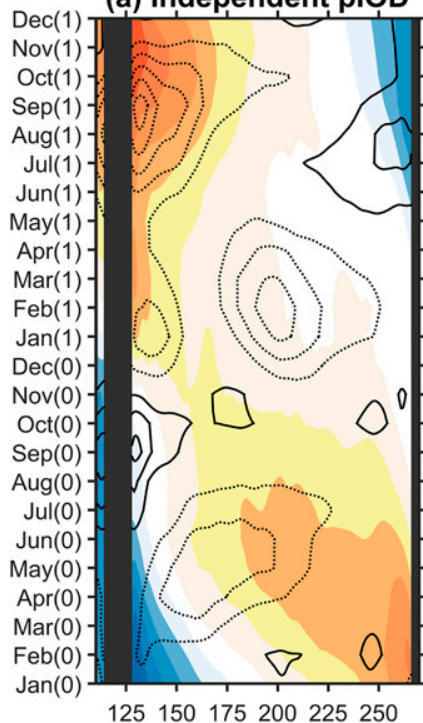

(d)

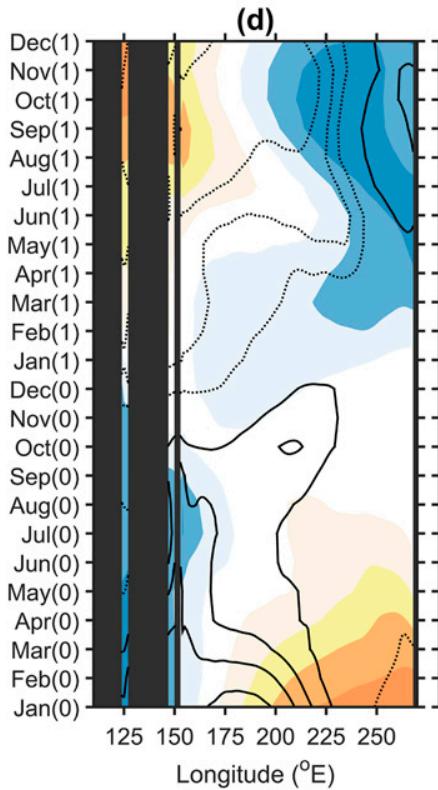

(b) Independent EI Nino

(c) pIOD-EI Nino

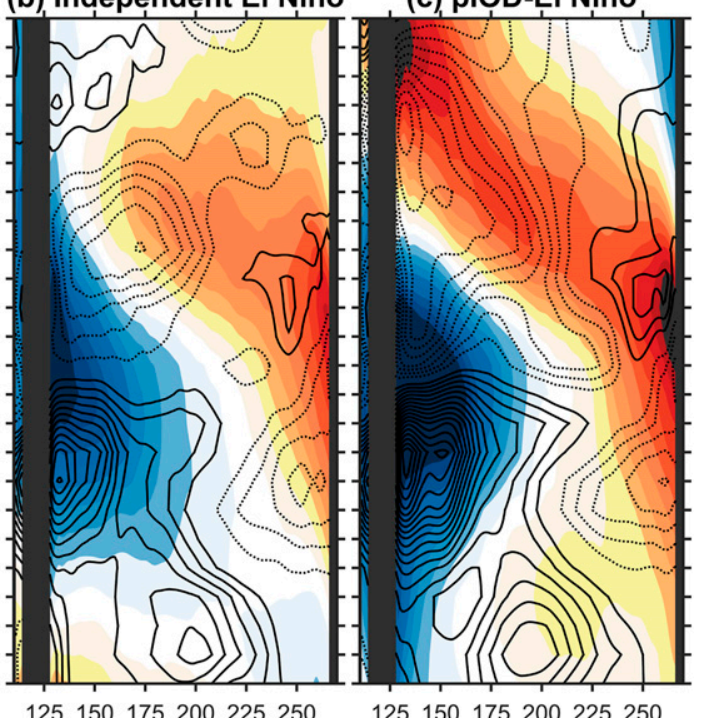

(f) (e)
)

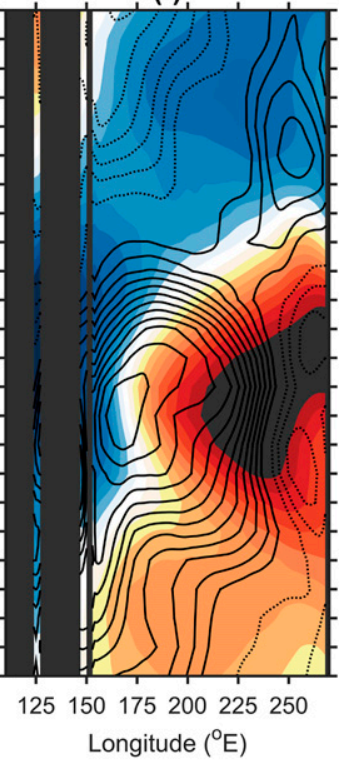

Longitude $\left({ }^{\circ} \mathrm{E}\right)$

$\tau_{\mathrm{x}}$ (contour; unit: $10^{-3} \mathrm{~Pa}$ ) $\mathrm{SSH}$ (shading; unit: $\mathrm{cm}$ )

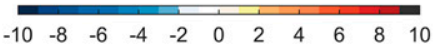

FIG. 11. Time-longitude plots of meridional-average SLAs (color shading; $\mathrm{cm}$ ) and $\tau_{x}$ anomalies (contours; $10^{-3} \mathrm{~Pa}$; positive and negative values are plotted in solid and dashed, respectively; contour interval is 2$)$ over the latitudinal band of the NWPO $\left(5^{\circ}-15^{\circ} \mathrm{N}\right)$ derived from CESM-LE simulations for (a) independent pIOD events, (b) independent El Niño events, and (c) concurrent pIOD-El Niño events. (d)-(f) As in (a)-(c), but over the latitudinal band of the WEPO $\left(5^{\circ} \mathrm{S}-5^{\circ} \mathrm{N}\right)$.

based on observational data (Fig. S13). Such consistency confirms the dominance of the first-mode baroclinic ocean response to wind forcing in the variability of the WTPO sea level (e.g., Qiu and Lukas 1996; Qiu and Chen 2010, 2012; Li et al. 2012; Zhai et al. 2013). We also estimate the ITF transport using RGO model results (Fig. 13c). The simulated ITF transports derived from ECMWF-RGO and CCMP-RGO agree with each other for the period of 1993-2017, and the variability range is $\sim 5 \mathrm{~Sv}\left(1 \mathrm{~Sv} \equiv 10^{6} \mathrm{~m}^{3} \mathrm{~s}^{-1}\right)$, which is accordant with previous observational estimates (e.g., Meyers 1996; Sprintall et al. 2009; Liu et al. 2015; Susanto and Song 2015). More importantly, the simulated ITF can well reproduce its correlation with ENSO, showing 
(a) Independent pIOD

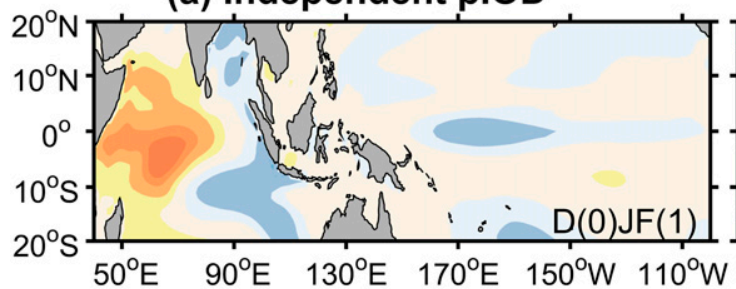

(b) Independent pIOD

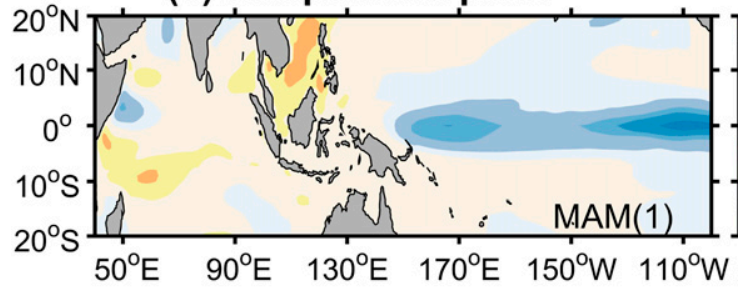

(c) Independent pIOD

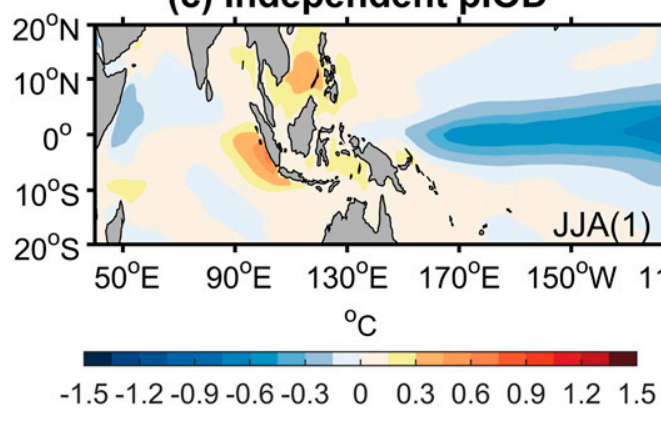

(d) Independent El Nino

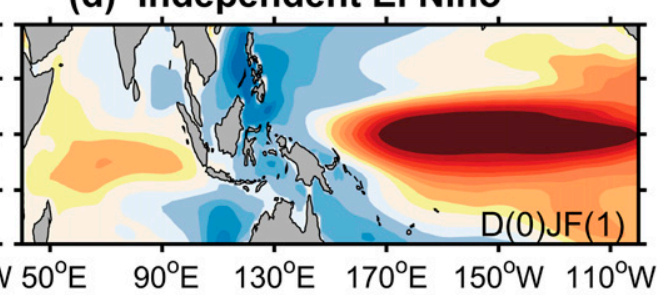

(e) Independent EI Nino

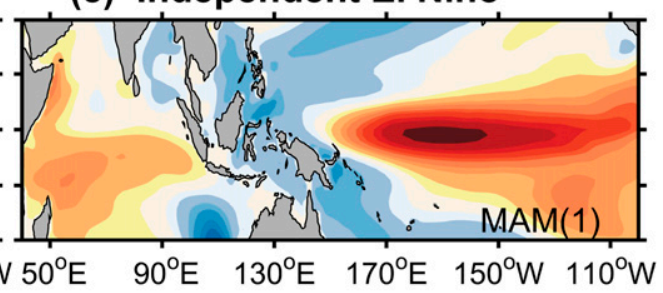

FIG. 12. Composite maps of sea surface temperature (SST) anomalies $\left({ }^{\circ} \mathrm{C}\right)$ derived from CESM-LE simulations for independent pIOD events during (a) D(0)JF(1), (b) MAM(1), and (c) JJA(1). (d)-(f) As in (a)-(c), but for independent El Niño events.

decreased transport in El Niño years and increased transport in La Niña years.

Given the good fidelity of the RGO model, experiments are performed and used to explore the underlying oceanic and atmospheric processes (summarized in Table 1). After a spinup of 20 years forced by monthly climatological winds of CESM-LE, the control run extends the spinup for 2 years under the same climatological winds. The pIOD run and the El Niño run use composite wind anomalies of the pIOD and El Niño composites (Fig. 10) respectively superimposed onto the climatological winds. The PO-wind run and the ITF run are used to isolate the effects of the Pacific winds and the ITF, respectively. In the PO-wind run, composite pIOD wind anomalies are only exerted in the Pacific Ocean $\left(105^{\circ} \mathrm{E}-70^{\circ} \mathrm{W}, 5^{\circ} \mathrm{S}-40^{\circ} \mathrm{N}\right.$ plus $140^{\circ} \mathrm{E}-$ $70^{\circ} \mathrm{W}, 40^{\circ}-5^{\circ} \mathrm{S}$ ), and in the ITF run composite pIOD wind anomalies are used only for the Indian Ocean $\left(30^{\circ}-105^{\circ} \mathrm{E}, 5^{\circ} \mathrm{S}-40^{\circ} \mathrm{N}\right.$ plus $\left.30^{\circ}-140^{\circ} \mathrm{E}, 40^{\circ}-5^{\circ} \mathrm{S}\right)$. Note that the Pacific wind anomalies of the PO-wind run contain not only atmospheric bridge effect of the pIOD but also the amplification by local air-sea interactions, and therefore it does not represent the pure effect of atmospheric processes. To be more accurate, it is the IOD-induced Pacific wind forcing effect that the POwind run measures. By contrast, the WTPO variability in the ITF run arises only from the ITF variability caused by the IOD, and therefore the ITF run isolates the pure ocean channel effect. The deviation of each experiment from the control run is adopted as the anomaly and used for analysis.

Figure 14 shows the composite ULTAs of the NWPO and the WEPO derived from different RGO model experiments. Results of the pIOD run and the El Niño run are overall consistent with CESM-LE simulations (Fig. 8), albeit showing some discrepancies in the NWPO, such as the positive anomalies in $\mathrm{SON}(0)$ unseen in CESM-LE. These differences are likely caused by relatively stronger Rossby wave propagation in the RGO model than in CESM (figures not shown), but they generally do not affect our results. In the NWPO (Fig. 14a), the IOD effect is by far weaker than the 

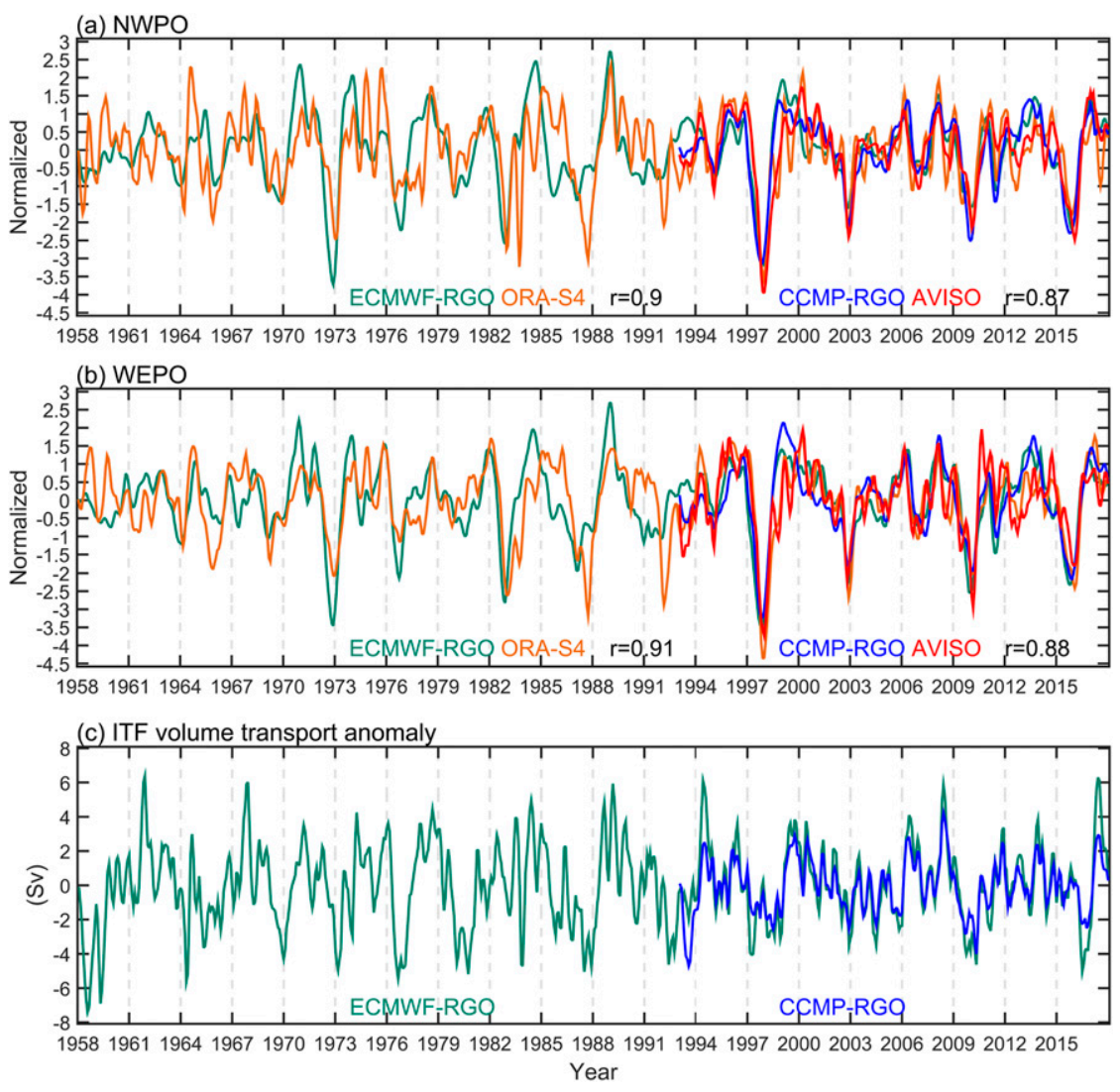

FIG. 13. Monthly SLAs averaged over the (a) NWPO and (b) WEPO derived from ORA-S4 and AIVSO, compared with monthly upper-layer thickness anomalies (ULTAs) of the 1.5layer reduced-gravity ocean (RGO) model simulations forced by ECMWF winds (ECMWFRGO) and CCMP winds (CCMP-RGO). All the variables in (a) and (b) are normalized by the standard deviation. The standard deviations for ECMWF-RGO, ORA-S4, CCMP-RGO, and AVISO are respectively $12.89 \mathrm{~m}, 6.49 \mathrm{~cm}, 6.90 \mathrm{~m}$, and $6.86 \mathrm{~cm}$ in (a), and $7.60 \mathrm{~m}, 4.92 \mathrm{~cm}$, $4.31 \mathrm{~m}$, and $5.29 \mathrm{~cm}$ in (b). (c) Monthly Indonesian Throughflow (ITF) transport anomalies at $5^{\circ} \mathrm{S}$ derived from ECMWF-RGO and CCMP-RGO.

El Niño event until the spring of year(1). The large positive ULTAs in year(1) are primarily caused by Pacific winds, and the ITF effect is negligible. The pIOD induces a ULT decrease of $-2.37 \mathrm{~m}$ in the WEPO in SON(0), accounting for $35.2 \%$ of the anomaly caused by the El Niño. The contributions of Pacific winds (POwind run) and the ITF (the ITF run) are $57.8 \%$ $(-1.37 \mathrm{~m})$ and $41.4 \%(-0.98 \mathrm{~m})$, respectively. By SON $(1)$, the pIOD causes ULTAs of +6.04 and $+5.00 \mathrm{~m}$ in the NWPO and the WEPO, respectively, which are predominantly achieved by modulating the Pacific winds with weak effect from the ITF.

Consistent with Fig. 14, spatial patterns of ULTAs confirm the dominant role of Pacific winds in conveying the IOD variability to the WTPO (Fig. 15). ULTAs in the ITF run are roughly $-0.8 \mathrm{~m}$ in $\operatorname{JJASON}(0)$ and weakened to $-0.4 \mathrm{~m}$ in year(1), contributing to the negative ULTAs in the PIOD run. Although small in amplitude, the negative equatorial SLAs (indicating upwelling Kelvin waves) caused by the pIOD through the ocean channel process may trigger positive Bjerknes feedback between cold SST (Fig. 12a) and easterly winds (Fig. 10b) and plays an essential role in the El Niño-to-La Niña phase transition (Yuan et al. 2011, 2013).

We further examine the impacts of the IOD on the upper-ocean gyre circulation of the WTPO using the RGO experiments, by estimating anomalies of the NEC, NECC, SEC-N, SECC, and NBL (see section 2c for definitions). As shown in Fig. 16, anomalies of the several currents in the pIOD run are comparable in amplitude to those in the El Niño run and show dramatically different characteristics in timing. The pIOD causes the weakening of the NECC, SEC-N, and SECC by respectively $-4.16,-1.72$, and $-1.04 \mathrm{~Sv}$ in $\mathrm{SON}(0)$ and strengthening them by respectively $+3.33,+1.10$, 
TABLE 1. A list of the RGO experiments analyzed in this study.

\begin{tabular}{|c|c|}
\hline Experiments & Wind forcing \\
\hline CTRL run & Monthly climatology \\
\hline pIOD run & Composite pIOD anomalies plus climatology \\
\hline PO-wind run & $\begin{array}{l}\text { Composite pIOD anomalies exerted only in } \\
\text { the Pacific Ocean }\left(105^{\circ} \mathrm{E}-70^{\circ} \mathrm{W}, 5^{\circ} \mathrm{S}-40^{\circ} \mathrm{N}\right. \\
\left.\text { and } 140^{\circ} \mathrm{E}-70^{\circ} \mathrm{W}, 40^{\circ}-5^{\circ} \mathrm{S}\right) \text { plus climatology }\end{array}$ \\
\hline ITF run & $\begin{array}{l}\text { Composite pIOD anomalies exerted only in } \\
\text { the Indian Ocean }\left(30^{\circ}-105^{\circ} \mathrm{E}, 5^{\circ} \mathrm{S}-40^{\circ} \mathrm{N}\right. \\
\left.\text { and } 30^{\circ}-140^{\circ} \mathrm{E}, 40^{\circ}-5^{\circ} \mathrm{S}\right) \text { plus climatology }\end{array}$ \\
\hline El Niño run & $\begin{array}{l}\text { Composite El Niño anomalies plus } \\
\text { climatology }\end{array}$ \\
\hline
\end{tabular}

and $+2.24 \mathrm{~Sv}$ in SON(1). Note that the anomalies of the pIOD run and the El Niño run in the NECC can approximately offset each other, which may partly explain the strong event-by-event discrepancies in the observed NECC's response to different El Niño events (e.g., Johnson et al. 2002; Johnson and Proehl 2004; Hsin and Qiu 2012; Zhao et al. 2013; Song et al. 2018). In comparison, the responses of the NEC and the NBL to the IOD are weaker $\left[+0.19 \mathrm{~Sv}\right.$ and $-0.04^{\circ}$ in $\mathrm{SON}(0)$ ] relative to their seasonal variability amplitudes $\left(8.04 \mathrm{~Sv}\right.$ and $\left.1.04^{\circ}\right)$ and their responses to ENSO, respectively. These results are consistent with existing research suggesting the dominance of ENSO in interannual variability of the NEC transport and NBL (e.g., Qiu and Joyce 1992; Kim et al. 2004; Kashino et al. 2009; Qiu and Chen 2012; Zhai and Hu 2013). STDs of the NEC, NECC, SEC-N, SECC, and NBL variations caused by the pIOD account for $45.8 \%$, $69.4 \%, 75.6 \%, 76.1 \%$, and $23.1 \%$ of those caused by El Niño, respectively (Fig. 16f). The large differences among these currents can be understood by considering the distribution of SLAs. Stronger SLAs in the WEPO (Fig. 14) and the smaller $f$ work mutually to give rise to larger anomalies of the currents near the equator such as the SEC-N and NECC. Similar to the case of ULTAs, the pIOD causes anomalies of the SEC-N, NECC, and SECC mainly through modulating Pacific Ocean winds, and the effects through the ITF are relatively weak.

\section{Conclusions and discussion}

Interannual sea level and ocean circulation variabilities in the WTPO were mainly attributed to wind forcing by ENSO, and the possible impacts from the Indian Ocean were not sufficiently appreciated. By analyzing observational and reanalysis data and results of climate model experiments, this study attempts to evaluate the impacts of the IOD on sea level and major upper-ocean currents of the WTPO

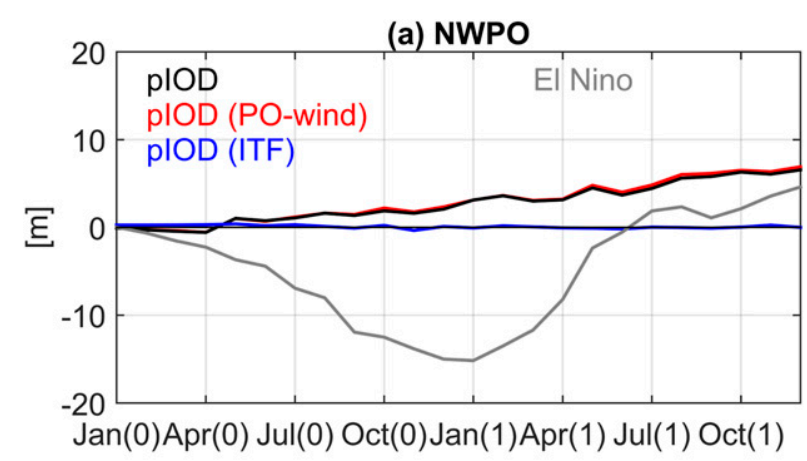

(b) WEPO

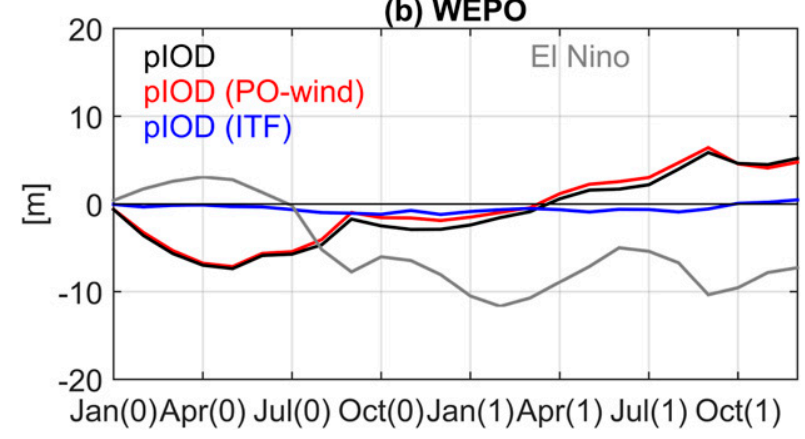

FIG. 14. Composite ULTAs (m) averaged in the (a) NWPO and (b) WEPO derived from pIOD run, PO-wind run (retaining wind variability in the Pacific Ocean), and ITF run (retaining wind variability in the Indian Ocean) of the RGO model forced by composite CESM-LE winds for independent pIOD events. Results of the El Niño run are also shown.

and explore the underlying oceanic and atmospheric processes.

Observational and reanalysis data over the past six decades reach consensus to show significant instantaneous and lagged correlations (around -0.60 and 0.40 , respectively) between the WTPO sea level and the IOD. Composite of 14 independent IOD events during 19582017 suggests that the pIOD tends to generate negative SLAs in the WTPO with amplitudes of $4-7 \mathrm{~cm}$ in its mature phase and large positive SLAs of $6-8 \mathrm{~cm}$ in the following year which are opposite in sign to El Niño signatures. Impacts of the IOD are stronger in the WEPO in year(0) and in the NWPO in year(1), respectively. Composite of the concurrent IOD-ENSO events appears to be the sum of the individual signatures of the IOD and ENSO, and shows more similarities to those of the IOD composite in the WTPO, particularly in year(1).

The prominent IOD signatures are confirmed by CESM-LE simulations in which 430 and 519 pIOD and nIOD events are identified. CESM-LE allows for removing the contaminated effects of the weak ENSO condition and isolates the IOD effects in a clean manner.

Further analysis suggests that the IOD impacts on the WTPO sea level are tightly associated with surface wind 
(a) PIOD

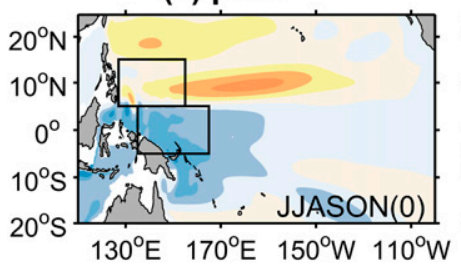

(b) pIOD

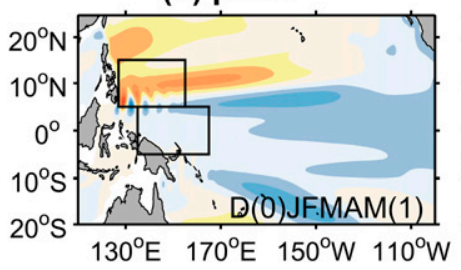

(c) pIOD

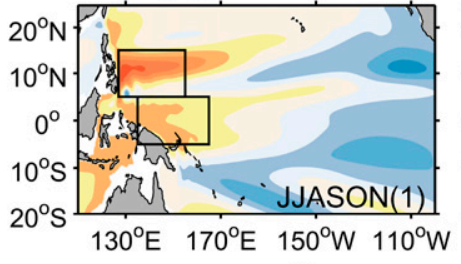

$\mathrm{m}$ (d) pIOD (PO-wind)

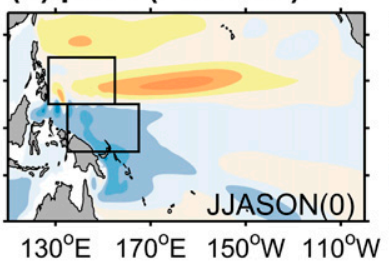

(e) pIOD (PO-wind)

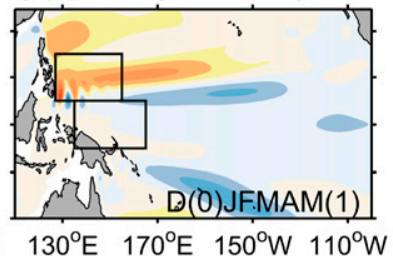

(f) pIOD (PO-wind)

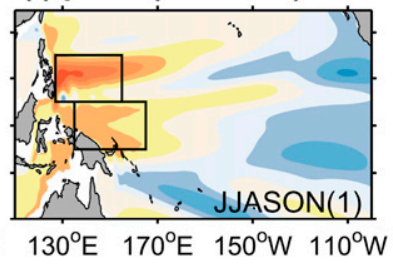

(g) pIOD (ITF)

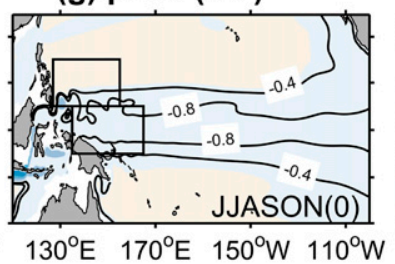

(h) pIOD (ITF)

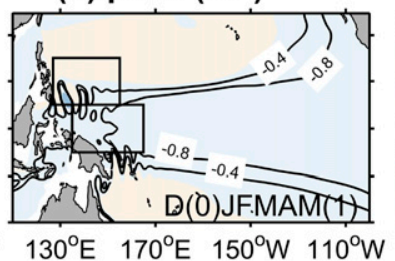

(i) pIOD (ITF)

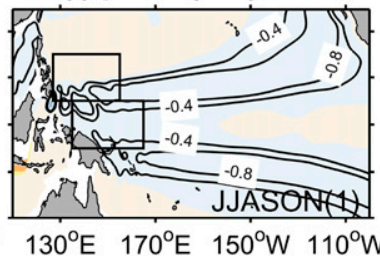

(j) El Nino

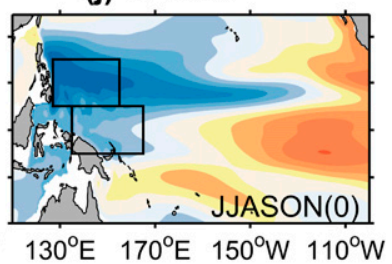

(k) El Nino

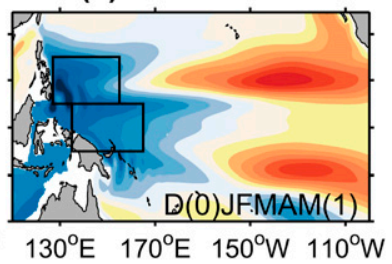

(I) El Nino

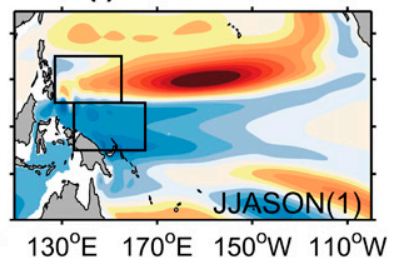

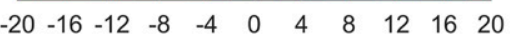

FIG. 15. Composite maps of ULTAs (m) derived from the pIOD run during (a) JJASON(0), (b) D(0)JFMAM(1), and (c) JJASON(1). (d)-(f) As in (a)-(c), but derived from the PO-wind run. (g)-(i) As in (a)-(c), but derived from the ITF run, with -0.8 and -0.4 plotted in solid contours. (j)-(1) As in (a)-(c), but derived from the El Niño run.

changes over the western-central tropical Pacific. The negative SLAs of the WTPO during JJASON(0) are caused by anomalous westerlies and positive off-equatorial $w_{E}$ anomalies associated with the pIOD. In the following year, positive SLAs in the WTPO correspond to enhanced Pacific trade winds over the tropical Pacific and negative $w_{E}$ anomalies off the equator. The enhanced Pacific trade winds are the manifestation of a La Niña event, which tends to occur in the year following a pIOD event in both observation and CESM-LE. The La Niña condition in the Pacific is likely the primary cause for the strong sea level rise of the WTPO and the positive WTPO-IOD correlation with a lag of $\sim 1$ year.

Using a 1.5-layer RGO model, sensitivity experiments are performed to explore the underlying processes. The results confirm that the IOD affects the WTPO sea level mainly through modulating the Pacific winds, and the ocean channel effect via the ITF is relatively weak. The ITF mainly acts to cause a sea level falling in the WTPO during the mature phase of the pIOD by letting in upwelling Kelvin waves from the eastern Indian Ocean, which may trigger Bjerknes feedback between cold SST and easterly winds and promote the phase transition to the La Niña condition. Regarding the circulation of the WTPO, the IOD also shows considerable impacts, causing anomalies of $1-4 \mathrm{~Sv}$ in volume transports of the SEC and the NECC. STDs of the NEC, NECC, SEC-N, SECC, and NBL variations caused by the PIOD account for $45.8 \%, 69.4 \%, 75.6 \%, 76.1 \%$, and $23.1 \%$ of those caused by El Niño, respectively. These current anomalies are also mainly achieved by modulating Pacific Ocean winds, with rather limited effects via the ITF.

An interesting question arising immediately from the present study is whether the Indian Ocean decadal variability can modulate sea level and gyre circulation of the WTPO. Recent studies suggested that the external forcing by greenhouse gases and aerosols have amplified the tropical Indian Ocean decadal-interdecadal variability (e.g., Dong and McPhaden 2016; Zhang et al. 2018; Li et al. 2018), which plays a more vital role in affecting regional and global climate (e.g., Luo et al. 2012; Han et al. 2014). It is natural to envision that a more dynamically active Indian Ocean has exerted strong impacts on the WTPO after the 1980s, although the Pacific Ocean is still dominated by intrinsic climate modes such as the interdecadal Pacific oscillation (e.g., Zhang and Church 2012; Han et al. 2014; Moon et al. 2015; Wu et al. 2017; Zhai et al. 2018). By analyzing 

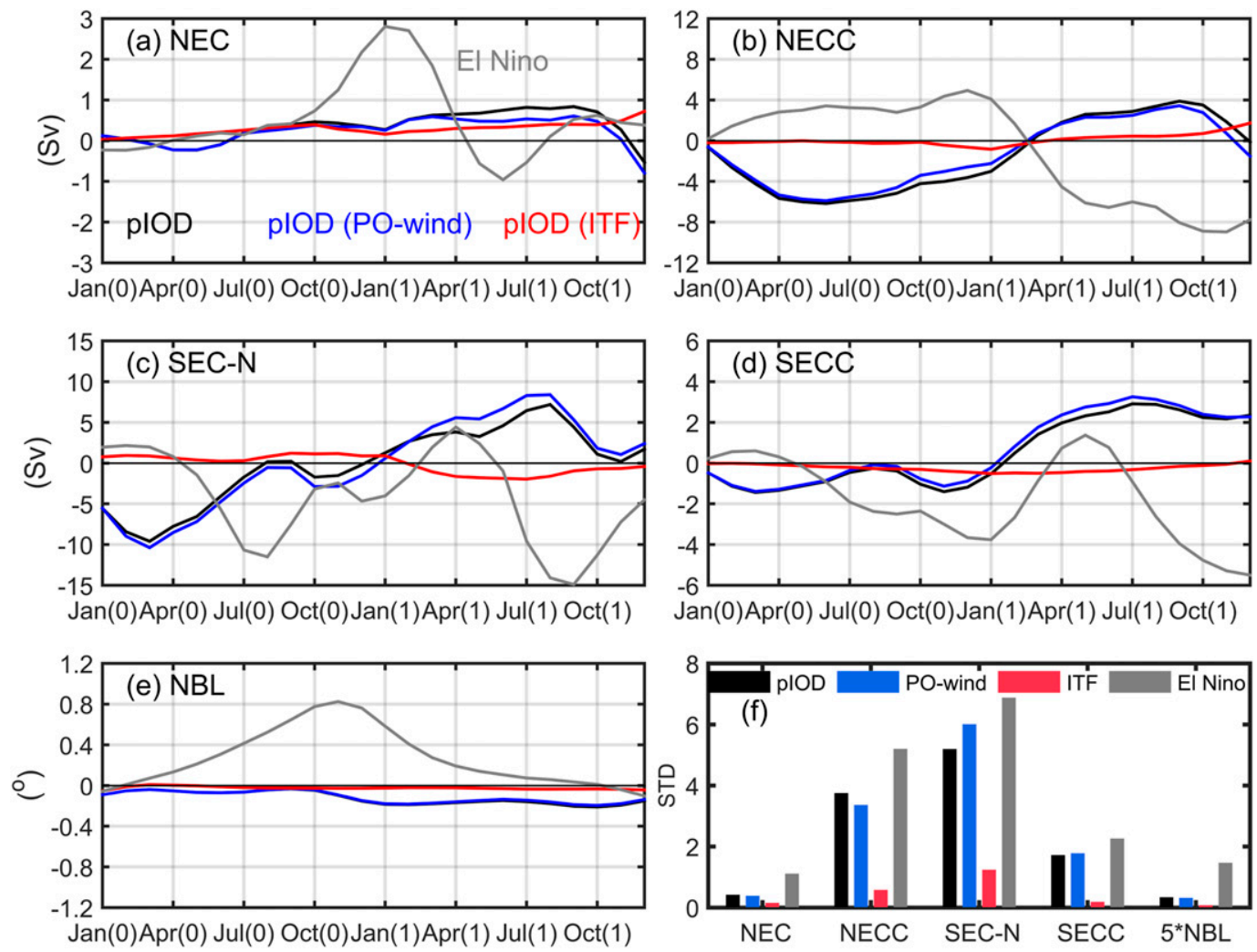

FIG. 16. Anomalies of the (a) NEC, (b) NECC, (c) SEC-N, and (d) SECC volume transports and (e) the NBL derived from the pIOD run, PO-wind run, ITF run, and El Niño run. (f) Standard deviations of the variables shown in (a)-(e). NEC: North Equatorial Current, NECC: North Equatorial Countercurrent, SEC-N: northern branch of South Equatorial Current, SECC: South Equatorial Countercurrent, NBL: the NEC's bifurcation latitude.

results from coupled model pacemaker experiments, Zhang et al. (2019) confirmed that warmer tropical Indian Ocean exerts influence on the Pacific response to anthropogenic greenhouse gas warming through an interbasin thermostat mechanism. Naturally, it is also interesting to further explore the future change of influence of the Indian Ocean on WTPO sea level and gyre circulation in the twenty-first century under the warming climate. Also, $\mathrm{Hu}$ and Fedorov (2019) suggested that the Indian Ocean warming can intensify the Atlantic meridional overturning circulation (AMOC) by reducing rainfall over the tropical Atlantic and enhancing westerly winds over the subpolar North Atlantic. They highlighted the atmospheric teleconnections in the linkage between the AMOC and the Indian Ocean. However, previous studies suggested that Agulhas Leakage (e.g., Gordon 1986; Beal et al. 2011) has an effect on interannual to decadal AMOC transport and may have contributed to the recovery of the AMOC after glacial periods during glacial terminations (e.g., Peeters et al. 2004; Biastoch et al. 2008).

Overall, our study provides the first description for the impacts of the IOD on WTPO sea level and major upper-ocean currents and may improve our understanding of the interannual variability of the WTPO by considering interbasin climate interactions. Considering that the main analysis of this study relies on CESM-LE simulations, we further validate the spatial pattern and magnitude of wind anomalies associated with IOD and ENSO. Regress anomalies of CESM-LE surface winds are broadly consistent with those based on ECMWF and CCMP in spatial pattern, except for with stronger amplitude (Figs. S14-S16). This small inconsistency may be due to the insufficient model simulation capability or fewer observation samples, but it does not affect our conclusions. There are many opportunities in the future to improve the present study of the IOD impacts by using a model of higher resolution and complexity (rather than the simplified dynamical RGO model) that is able to better represent the complicated ocean teleconnection processes through the ITF region. The amplification of the ocean teleconnection signatures through local air-sea feedbacks (Yuan et al. 2011, 2013) and its role played during the ENSO phase transition are to be investigated with climate models. Additionally, given the remarkable climatic and ecological impacts of the low-latitude Pacific 
western boundary currents (e.g., Lukas et al. 1996; Li and Wang 2012; Hu et al. 2015), their responses to the IOD should be explored, particularly for the Mindanao Current that is the major source of the ITF and the nascent Kuroshio (Gordon et al. 2014), which strongly modulates the subtropical and South China Sea climates. Note that the impacts of the IOD on the southwestern tropical Pacific SLAs are not included in this study. This is mainly because the SLA responses in observation and CESM-LE simulations are obviously different during JJASON(1) (Figs. 5c and 9c), which indicates a more complex mechanism and may be an interesting theme for a future study.

Acknowledgments. The authors thank two anonymous reviewers for providing insightful comments. This study is supported by the National Key R\&D Program of China (2019YFA0606702) and Natural Science Foundation of China (Grants 41730534, 41806014, 41776001, 41806001). HadISST data are downloaded from the Met Office website https://www.metoffice.gov.uk/hadobs/. AVISO data are available at https://www.aviso.altimetry.fr/en/home.html. CCMP winds are obtained from NOAA's PSD website http://www.remss.com/measurements/ccmp/. Wind stress and sea level data of ORA-S4 are downloaded from https:// apps.ecmwf.int/datasets/ and http://apdrc.soest.hawaii.edu/ datadoc/ecmwf_oras4.php, respectively. CESM-LE simulations are available from http://www.cesm.ucar.edu/ projects/community-projects/LENS/. Data analysis and graphing of this study were completed using Matlab R2015a.

\section{REFERENCES}

Alexander, M., and J. Scott, 2002: The influence of ENSO on airsea interaction in the Atlantic. Geophys. Res. Lett., 29, 1701, https://doi.org/10.1029/2001GL014347.

— I. Bladé, M. Newman, J. R. Lanzante, N. C. Lau, and J. D. Scott, 2002: The atmospheric bridge: The influence of ENSO teleconnections on air-sea interaction over the global oceans. J. Climate, 15, 2205-2231, https://doi.org/10.1175/1520-0442(2002) 015<2205:TABTIO > 2.0.CO;2.

Annamalai, H., R. Murtugudde, J. Potemra, S. Xie, P. Liu, and B. Wang, 2003: Coupled dynamics over the Indian Ocean: Spring initiation of the zonal mode. Deep-Sea Res. II, 50, 23052330, https://doi.org/10.1016/S0967-0645(03)00058-4.

—, S. P. Xie, J. P. McCreary, and R. Murtugudde, 2005: Impact of Indian Ocean sea surface temperature on developing El Niño. J. Climate, 18, 302-319, https://doi.org/10.1175/JCLI-3268.1.

Atlas, R., R. N. Hoffman, J. Ardizzone, S. M. Leidner, J. C. Jusem, D. K. Smith, and D. Gombos, 2011: A cross-calibrated, multiplatform ocean surface wind velocity product for meteorological and oceanographic applications. Bull. Amer. Meteor. Soc., 92, 157-174, https://doi.org/10.1175/2010BAMS2946.1.

Austin, P. C., and J. V. Tu, 2004: Bootstrap methods for developing predictive models. Amer. Stat., 58, 131-137, https://doi.org/ 10.1198/0003130043277.
Balmaseda, M. A., K. Mogensen, and A. T. Weaver, 2013: Evaluation of the ECMWF ocean reanalysis system ORAS4. Quart. J. Roy. Meteor. Soc., 139, 1132-1161, https://doi.org/ 10.1002/qj.2063.

Beal, L. M., W. P. M. De Ruijter, A. Biastoch, and R. Zahn, 2011: On the role of the Agulhas system in ocean circulation and climate. Nature, 472, 429-436, https://doi.org/ 10.1038/nature09983.

Biastoch, A., C. W. Böning, and J. R. E. Lutjeharms, 2008: Agulhas leakage dynamics affects decadal variability in Atlantic overturning circulation. Nature, 456, 489-492, https://doi.org/10.1038/nature07426.

Cai, W., and Y. Qiu, 2013: An observation-based assessment of nonlinear feedback processes associated with the Indian Ocean dipole. J. Climate, 26, 2880-2890, https://doi.org/ 10.1175/JCLI-D-12-00483.1.

- and Coauthors, 2019: Pantropical climate interactions. Science, 363, eaav4236, https://doi.org/10.1126/science.aav4236.

Cazenave, A., and F. Remy, 2011: Sea level and climate: Measurements and causes of changes. Wiley Interdiscip. Rev.: Climate Change, 2, 647-662, https://doi.org/10.1002/wcc.139.

Chen, M., and T. Li, 2018: Why 1986 El Niño and 2005 La Niña evolved different from a typical El Niño and La Niña. Climate Dyn., 51, 4309-4327, https://doi.org/10.1007/s00382-017-3852-1.

Chen, Z., and L. Wu, 2011: Dynamics of the seasonal variation of the North Equatorial Current bifurcation. J. Geophys. Res., 116, C02018, https://doi.org/10.1029/2010JC006664. , and - 2012: Long-term change of the Pacific North Equatorial Current bifurcation in SODA. J. Geophys. Res., 117, C06016, https://doi.org/10.1029/2011JC007814.

_ and - 2015: Seasonal variation of the Pacific South Equatorial Current bifurcation. J. Phys. Oceanogr., 45, 17571770, https://doi.org/10.1175/JPO-D-14-0085.1.

Clarke, A. J., 1991: On the reflection and transmission of lowfrequency energy at the irregular western Pacific Ocean boundary. J. Geophys. Res., 96, 3289-3305, https://doi.org/ 10.1029/90JC00985.

Clement, A. C., R. Seager, and R. Murtugudde, 2005: Why are there tropical warm pools? J. Climate, 18, 5294-5311, https:// doi.org/10.1175/JCLI3582.1.

Dayan, H., T. Izumo, J. Vialard, M. Lengaigne, and S. Masson, 2015: Do regions outside the tropical Pacific influence ENSO through atmospheric teleconnections? Climate Dyn., 45, 583601, https://doi.org/10.1007/s00382-014-2254-x.

Dee, D. P., and Coauthors, 2011: The ERA-Interim reanalysis: Configuration and performance of the data assimilation system. Quart. J. Roy. Meteor. Soc., 137, 553-597, https://doi.org/ 10.1002/qj.828.

Dong, L., and M. J. McPhaden, 2016: Interhemispheric SST gradient trends in the Indian Ocean prior to and during the recent global warming hiatus. J. Climate, 29, 9077-9095, https:// doi.org/10.1175/JCLI-D-16-0130.1.

Du, Y., S.-P. Xie, G. Huang, and K. Hu, 2009: Role of air-sea interaction in the long persistence of El Niño-induced North Indian Ocean warming. J. Climate, 22, 2023-2038, https:// doi.org/10.1175/2008JCLI2590.1.

Duan, J., Y. Li, F. Wang, and Z. Chen, 2019a: Decadal variations of the Mindanao Current during 1960-2010. J. Geophys. Res. Oceans, 124, 2660-2678, https://doi.org/ 10.1029/2019JC014975.

,,--- , and,$- 2019 \mathrm{~b}$ : Multidecadal change of the Mindanao Current: Is there a robust trend? Geophys. Res. Lett., 46, 6755-6764, https://doi.org/10.1029/2019GL083090. 
Gordon, A. L., 1986: Interocean exchange of thermocline water. J. Geophys. Res., 91, 5037-5046, https://doi.org/10.1029/ JC091iC04p05037.

- P. Plament, C. Villanoy, and L. Centurioni, 2014: The nascent Kuroshio of Lamon Bay. J. Geophys. Res. Oceans, 119, 42514263, https://doi.org/10.1002/2014JC009882.

Han, W., and Coauthors, 2014: Intensification of decadal and multidecadal sea level variability in the western tropical Pacific during recent decades. Climate Dyn., 43, 1357-1379, https:// doi.org/10.1007/s00382-013-1951-1.

, G. A. Meehl, D. Stammer, A. Hu, B. Hamlington, J. Kenigson, H. Palanisamy, and P. Thompson, 2017: Spatial patterns of sea level variability associated with natural internal climate modes. Surv. Geophys., 38, 217-250, https:// doi.org/10.1007/s10712-016-9386-y.

Hsin, Y.-C., and B. Qiu, 2012: The impact of Eastern-Pacific versus Central-Pacific El Niños on the North Equatorial Countercurrent in the Pacific Ocean. J. Geophys. Res., 117, C11017, https://doi.org/ 10.1029/2012JC008362.

Hu, D., and Coauthors, 2015: Pacific western boundary currents and their roles in climate. Nature, 522, 299-308, https://doi.org/ 10.1038/nature14504.

Hu, S., and A. V. Fedorov, 2019: Indian Ocean warming can strengthen the Atlantic meridional overturning circulation. Nat. Climate Change, 9, 747-751, https://doi.org/10.1038/s41558-019-0566-x.

$\mathrm{Hu}, \mathrm{X}$., and Coauthors, 2019: Interannual variability of the Sulawesi Sea circulation forced by Indo-Pacific planetary waves. J. Geophys. Res. Oceans, 124, 1616-1633, https:// doi.org/10.1029/2018JC014356.

Hurrell, J. W., and Coauthors, 2013: The Community Earth System Model: A framework for collaborative research. Bull. Amer. Meteor. Soc., 94, 1339-1360, https://doi.org/10.1175/BAMS-D12-00121.1.

Izumo, T., and Coauthors, 2010: Influence of the state of the Indian Ocean Dipole on the following year's El Niño. Nat. Geosci., 3, 168-172, https://doi.org/10.1038/ngeo760.

- M. Lengaigne, J. Vialard, J.-J. Luo, T. Yamagata, and G. Madec, 2014: Influence of Indian Ocean Dipole and Pacific recharge on following year's El Niño: Interdecadal robustness. Climate Dyn., 42, 291-310, https://doi.org/10.1007/s00382-0121628-1.

_ _ J. Vialard, H. Dayan, M. Lengaigne, and I. Suresh, 2016: A simple estimation of equatorial Pacific response from windstress to untangle Indian Ocean dipole and basin influences on El Niño. Climate Dyn., 46, 2247-2268, https://doi.org/10.1007/ s00382-015-2700-4.

Jin, F.-F., 1997: An equatorial ocean recharge paradigm for ENSO. Part I: Conceptual model. J. Atmos. Sci., 54, 811-829, https://doi.org/10.1175/1520-0469(1997)054<0811:AEORPF> 2.0.CO;2

Johnson, E. S., and J. A. Proehl, 2004: Tropical instability wave variability in the Pacific and its relation to large-scale currents. J. Phys. Oceanogr., 34, 2121-2147, https://doi.org/10.1175/ 1520-0485(2004)034<2121:TIWVIT>2.0.CO;2.

Johnson, G. C., B. M. Sloyan, W. S. Kessler, and K. E. McTaggart, 2002: Direct measurements of upper ocean currents and water properties across the tropical Pacific during the 1990s. Prog. Oceanogr., 52, 31-61, https://doi.org/10.1016/S0079-6611(02) 00021-6.

Johnston, T. M. S., and M. A. Merrifield, 2000: Interannual geostrophic current anomalies in the near-equatorial western Pacific. J. Phys. Oceanogr., 30, 3-14, https://doi.org/10.1175/ 1520-0485(2000)030<0003:IGCAIT >2.0.CO;2.
Jourdain, N. C., M. Lengaigne, J. Vialard, T. Izumo, and A. Sen Gupta, 2016: Further insights on the influence of the Indian Ocean dipole on the following year's ENSO from observations and CMIP5 models. J. Climate, 29, 637-658, https://doi.org/ 10.1175/JCLI-D-15-0481.1.

Kashino, Y., N. España, F. Syamsudin, K. J. Richards, T. Jensen, P. Dutrieux, and A. Ishida, 2009: Observations of the North Equatorial Current, Mindanao Current, and Kuroshio current system during the 2006/07 El Niño and 2007/08 La Niña. J. Oceanogr., 65, 325-333, https://doi.org/10.1007/s10872-009-0030-z.

Kay, J. E., and Coauthors, 2015: The Community Earth System Model (CESM) large ensemble project: A community resource for studying climate change in the presence of internal climate variability. Bull. Amer. Meteor. Soc., 96, 1333-1349, https://doi.org/10.1175/BAMS-D-13-00255.1.

Kessler, W. S., 1990: Observations of long Rossby waves in the northern tropical Pacific. J. Geophys. Res., 95, 5183-5217, https://doi.org/10.1029/JC095iC04p05183.

_ and B. A. Taft, 1987: Dynamic heights and zonal geostrophic transports in the central tropical Pacific during 1979-84. J. Phys. Oceanogr., 17, 97-122, https://doi.org/10.1175/15200485(1987)017<0097:DHAZGT>2.0.CO;2.

Kim, Y. Y., T. Qu, T. Jensen, T. Miyama, H. Mitsudera, H.-W. Kang, and A. Ishida, 2004: Seasonal and interannual variations of the North Equatorial Current bifurcation in a highresolution OGCM. J. Geophys. Res., 109, C03040, https:// doi.org/10.1029/2003JC002013.

Klein, S. A., B. J. Soden, and N.-C. Lau, 1999: Remote sea surface temperature variations during ENSO: Evidence for a tropical atmospheric bridge. J. Climate, 12, 917-932, https://doi.org/ 10.1175/1520-0442(1999)012<0917:RSSTVD $>2.0 . C O ; 2$.

Kug, J.-S., and I.-S. Kang, 2006: Interactive feedback between ENSO and the Indian Ocean. J. Climate, 19, 1784-1801, https://doi.org/10.1175/JCLI3660.1.

, B. P. Kirtman, and I.-S. Kang, 2006: Interactive feedback between ENSO and the Indian Ocean in an interactive ensemble coupled model. J. Climate, 19, 6371-6381, https:// doi.org/10.1175/JCLI3980.1.

Lamarque, J.-F., and Coauthors, 2010: Historical (1850-2000) gridded anthropogenic and biomass burning emissions of reactive gases and aerosols: Methodology and application. Atmos. Chem. Phys., 10, 7017-7039, https://doi.org/10.5194/acp-10-7017-2010.

Lau, N.-C., and M. J. Nath, 2003: Atmosphere-ocean variations in the Indo-Pacific sector during ENSO episodes. J. Climate, 16, 3-20, https://doi.org/10.1175/1520-0442(2003)016<0003: AOVITI>2.0.CO;2.

Le Traon, P. Y., F. Nadal, and N. Ducet, 1998: An improved mapping method of multisatellite altimeter data. J. Atmos. Oceanic Technol., 15, 522-534, https://doi.org/10.1175/15200426(1998)015<0522:AIMMOM >2.0.CO;2.

Li, Y., and F. Wang, 2012: Spreading and salinity change of North Pacific Tropical Water in the Philippine Sea. J. Oceanogr., 68 , 439-452, https://doi.org/10.1007/s10872-012-0110-3.

—, , and F. Zhai, 2012: Interannual variations of subsurface spiciness in the Philippine Sea: Observations and mechanism. J. Phys. Oceanogr., 42, 1022-1038, https://doi.org/10.1175/ JPO-D-12-06.1.

, W. Han, and L. Zhang, 2017: Enhanced decadal warming of the southeast Indian Ocean during the recent global surface warming slowdown. Geophys. Res. Lett., 44, 9876-9884, https://doi.org/10.1002/2017GL075050.

- — , A. Hu, G. A. Meehl, and F. Wang, 2018: Multidecadal changes of the upper Indian Ocean heat content during 
1965-2016. J. Climate, 31, 7863-7884, https://doi.org/10.1175/ JCLI-D-18-0116.1.

Liu, Q.-Y., M. Feng, D. Wang, and S. Wijffels, 2015: Interannual variability of the Indonesian Throughflow transport: A revisit based on 30 year expendable bathythermograph data. J. Geophys. Res. Oceans, 120, 8270-8282, https://doi.org/ 10.1002/2015JC011351.

Lukas, R., 1988: Interannual fluctuations of the Mindanao Current inferred from sea level. J. Geophys. Res., 93, 6744-6748, https://doi.org/10.1029/JC093iC06p06744.

_ - T. Yamagata, and J. P. McCreary, 1996: Pacific low-latitude western boundary currents and the Indonesian Throughflow. J. Geophys. Res., 101, 12 209-12 216, https://doi.org/10.1029/ 96JC01204.

Luo, J.-J., R. Zhang, S. K. Behera, Y. Masumoto, F.-F. Jin, R. Lukas, and T. Yamagata, 2010: Interaction between El Niño and extreme Indian Ocean dipole. J. Climate, 23, 726742, https://doi.org/10.1175/2009JCLI3104.1.

_ , W. Sasaki, and Y. Masumoto, 2012: Indian Ocean warming modulates Pacific climate change. Proc. Natl. Acad. Sci. USA, 109, 18 701-18 706, https://doi.org/10.1073/pnas.1210239109.

Meng, L., W. Zhuang, W. Zhang, A. Ditri, and X.-H. Yan, 2019: Decadal sea level variability in the Pacific Ocean: Origins and climate mode contributions. J. Atmos. Oceanic Technol., 36, 689-698, https://doi.org/10.1175/JTECH-D-18-0159.1.

Merrifield, M., B. Kilonsky, and S. Nakahara, 1999: Interannual sea level changes in the tropical Pacific associated with ENSO. Geophys. Res. Lett., 26, 3317-3320, https://doi.org/10.1029/ 1999GL010485.

_ 2011: A shift in western tropical Pacific sea level trends during the 1990s. J. Climate, 24, 4126-4138, https://doi.org/10.1175/ 2011JCLI3932.1.

Meyers, G., 1979: On the annual Rossby wave in the tropical North Pacific Ocean. J. Phys. Oceanogr., 9, 663-674, https://doi.org/ 10.1175/1520-0485(1979)009<0663:OTARWI >2.0.CO;2.

_ 1996: Variation of Indonesian throughflow and the El NiñoSouthern Oscillation. J. Geophys. Res., 101, 12 255-12 263, https://doi.org/10.1029/95JC03729.

Moon, J., Y. T. Song, and H. Lee, 2015: PDO and ENSO modulations intensified decadal sea level variability in the tropical Pacific. J. Geophys. Res. Oceans, 120, 8229-8237, https:// doi.org/10.1002/2015JC011139.

Nerem, R. S., D. P. Chambers, C. Choe, and G. T. Mitchum, 2010: Estimating mean sea level change from the TOPEX and Jason altimeter missions. Mar. Geod., 33, 435-446, https://doi.org/ 10.1080/01490419.2010.491031.

Ohba, M., and H. Ueda, 2007: An impact of SST anomalies in the Indian Ocean in acceleration of the El Niño to La Niña transition. $J$. Meteor. Soc. Japan, 85, 335-348, https://doi.org/10.2151/jmsj.85.335.

Peeters, F. J. C., R. Acheson, G.-J. A. Brummer, W. P. M. de Ruijter, R. R. Schneider, G. M. Ganssen, E. Ufkes, and D. Kroon, 2004: Vigorous exchange between the Indian and Atlantic oceans at the end of the past five glacial periods. Nature, 430, 661-665, https://doi.org/10.1038/nature02785.

Picaut, J., 1997: An advective-reflective conceptual model for the oscillatory nature of the ENSO. Science, 277, 663-666, https:// doi.org/10.1126/science.277.5326.663.

Qiu, B., and T. M. Joyce, 1992: Interannual variability in the midand low-latitude western North Pacific. J. Phys. Oceanogr., 22, 1062-1079, https://doi.org/10.1175/1520-0485(1992)022<1062: IVITMA $>2.0 . \mathrm{CO} ; 2$

_ _ and R. Lukas, 1996: Seasonal and interannual variability of the North Equatorial Current, the Mindanao Current, and the
Kuroshio along the Pacific western boundary. J. Geophys. Res., 101, 12 315-12 330, https://doi.org/10.1029/95JC03204. , and S. Chen, 2010: Interannual-to-decadal variability in the bifurcation of the North Equatorial Current off the Philippines. J. Phys. Oceanogr., 40, 2525-2538, https:// doi.org/10.1175/2010JPO4462.1.

_ and - 2012: Multidecadal sea level and gyre circulation variability in the northwestern tropical Pacific Ocean. J. Phys. Oceanogr., 42, 193-206, https://doi.org/10.1175/ JPO-D-11-061.1.

- — L L. Wu, and S. Kida, 2015: Wind- versus eddy-forced regional sea level trends and variability in the North Pacific Ocean. J. Climate, 28, 1561-1577, https://doi.org/10.1175/ JCLI-D-14-00479.1.

Rayner, N. A., 2003: Global analyses of sea surface temperature, sea ice, and night marine air temperature since the late nineteenth century. J. Geophys. Res., 108, 4407, https://doi.org/ 10.1029/2002JD002670.

Ren, Q., Y. Li, F. Wang, L. Song, C. Liu, and F. Zhai, 2018: Seasonality of the Mindanao Current/Undercurrent system. J. Geophys. Res. Oceans, 123, 1105-1122, https://doi.org/ 10.1002/2017JC013474.

Saji, N. H., and T. Yamagata, 2003: Structure of SST and surface wind variability during Indian Ocean dipole mode events: COADS observations. J. Climate, 16, 2735-2751, https://doi.org/ 10.1175/1520-0442(2003)016<2735:SOSASW >2.0.CO;2.

_ B. N. Goswami, P. N. Vinayachandran, and T. Yamagata, 1999: A dipole mode in the tropical Indian Ocean. Nature, 401, 360-363, https://doi.org/10.1038/43854.

Santoso, A., W. Cai, M. H. England, and S. J. Phipps, 2011: The role of the Indonesian Throughflow on ENSO dynamics in a coupled climate model. J. Climate, 24, 585-601, https://doi.org/ 10.1175/2010JCLI3745.1.

Schott, F. A., S.-P. Xie, and J. P. McCreary, 2009: Indian Ocean circulation and climate variability. Rev. Geophys., 47, RG1002, https://doi.org/10.1029/2007RG000245.

Schwarzkopf, F. U., and C. W. Böning, 2011: Contribution of Pacific wind stress to multi-decadal variations in upper-ocean heat content and sea level in the tropical south Indian Ocean. Geophys. Res. Lett., 38, L12602, https://doi.org/10.1029/ 2011 GL047651.

Shinoda, T., H. H. Hendon, and M. A. Alexander, 2004: Surface and subsurface dipole variability in the Indian Ocean and its relation with ENSO. Deep-Sea Res. I, 51, 619-635, https:// doi.org/10.1016/j.dsr.2004.01.005.

Song, L., Y. Li, F. Wang, J. Wang, and C. Liu, 2018: Subsurface structure and variability of the zonal currents in the northwestern tropical Pacific Ocean. Deep-Sea Res. I, 141, 11-23, https://doi.org/10.1016/j.dsr.2018.09.004.

Sprintall, J., S. E. Wijffels, R. Molcard, and I. Jaya, 2009: Direct estimates of the Indonesian Throughflow entering the Indian Ocean: 2004-2006. J. Geophys. Res., 114, C07001, https:// doi.org/10.1029/2008JC005257.

Stammer, D., A. Cazenave, R. M. Ponte, and M. E. Tamisiea, 2013: Causes for contemporary regional sea level changes. Annu. Rev. Mar. Sci., 5, 21-46, https://doi.org/10.1146/ annurev-marine-121211-172406.

Susanto, R. D., and Y. T. Song, 2015: Indonesian throughflow proxy from satellite altimeters and gravimeters. J. Geophys. Res. Oceans, 120, 2844-2855, https://doi.org/10.1002/2014JC010382.

Uppala, S. M., and Coauthors, 2005: The ERA-40 Re-Analysis. Quart. J. Roy. Meteor. Soc., 131, 2961-3012, https://doi.org/ 10.1256/qj.04.176. 
Wang, C., 2019: Three-ocean interactions and climate variability: A review and perspective. Climate Dyn., 53, 5119-5136, https:// doi.org/10.1007/s00382-019-04930-x.

Widlansky, M. J., A. Timmermann, S. McGregor, M. F. Stuecker, and W. Cai, 2014: An interhemispheric tropical sea level seesaw due to El Niño taimasa. J. Climate, 27, 1070-1081, https://doi.org/10.1175/JCLI-D-13-00276.1.

Wu, C. R., Y. L. Wang, Y. F. Lin, and S. Y. Chao, 2017: Intrusion of the Kuroshio into the South and East China Seas. Sci. Rep., 7, 7895, https://doi.org/10.1038/s41598-017-08206-4.

Xie, S.-P., K. Hu, J. Hafner, H. Tokinaga, Y. Du, G. Huang, and T. Sampe, 2009: Indian Ocean capacitor effect on Indo-western Pacific climate during the summer following El Niño. J. Climate, 22, 730-747, https://doi.org/10.1175/2008JCLI2544.1.

Yamagata, T., S. K. Behera, J.-J. Luo, S. Masson, M. R. Jury, and S. A. Rao, 2004: Coupled ocean-atmosphere variability in the tropical Indian Ocean. Earth's Climate: The Ocean-Atmosphere Interaction, Geophys. Monogr., Vol. 147, Amer. Geophys. Union, 189-211.

Yang, J., Q. Liu, S.-P. Xie, Z. Liu, and L. Wu, 2007: Impact of the Indian Ocean SST basin mode on the Asian summer monsoon. Geophys. Res. Lett., 34, L02708, https://doi.org/10.1029/2006GL028571.

Yuan, D., and Coauthors, 2011: Forcing of the Indian Ocean dipole on the interannual variations of the tropical Pacific Ocean: Roles of the Indonesian Throughflow. J. Climate, 24, 3593 3608, https://doi.org/10.1175/2011JCLI3649.1.

_ H. Zhou, and X. Zhao, 2013: Interannual climate variability over the tropical Pacific Ocean induced by the Indian Ocean dipole through the Indonesian Throughflow. J. Climate, 26, 2845-2861, https://doi.org/10.1175/JCLI-D-12-00117.1. , and Coauthors, 2018a: Observed transport variations in the Maluku Channel of the Indonesian Seas associated with western boundary current changes. J. Phys. Oceanogr., 48, 1803-1813, https://doi.org/10.1175/JPO-D-17-0120.1.

, X. Hu, P. Xu, X. Zhao, Y. Masumoto, and W. Han, 2018b: The IOD-ENSO precursory teleconnection over the tropical Indo-Pacific Ocean: Dynamics and long-term trends under global warming. J. Oceanol. Limnol., 36, 4-19, https://doi.org/ 10.1007/s00343-018-6252-4.

Zhai, F., and D. Hu, 2013: Revisit the interannual variability of the North Equatorial Current transport with ECMWF ORA-S3. J. Geophys. Res. Oceans, 118, 1349-1366, https://doi.org/ 10.1002/jgrc.20093.

— - - and T. Qu, 2013: Decadal variations of the North Equatorial Current in the Pacific at $137^{\circ}$ E. J. Geophys. Res. Oceans, 118, 4989-5006, https://doi.org/10.1002/jgrc.20391.

,-- , and P. Li, 2018: Decadal variations of the transport and bifurcation of the Pacific North Equatorial Current. J. Oceanogr., 74, 65-80, https://doi.org/10.1007/s10872-017-0441-1.

Zhang, L., F. J. Wang, Q. Wang, S. Hu, F. Wang, and D. Hu, 2017: Structure and variability of the North Equatorial Current/ Undercurrent from mooring measurements at $130^{\circ} \mathrm{E}$ in the western Pacific. Sci. Rep., 7, 46310, https://doi.org/10.1038/ SREP46310.

_ W. Han, and F. Sienz, 2018: Unraveling causes for the changing behavior of the tropical Indian Ocean in the past few decades. J. Climate, 31, 2377-2388, https://doi.org/10.1175/ JCLI-D-17-0445.1.

,-- K. B. Karnauskas, G. A. Meehl, A. Hu, N. Rosenbloom, and T. Shinoda, 2019: Indian Ocean warming trend reduces Pacific warming response to anthropogenic greenhouse gases: An interbasin thermostat mechanism. Geophys. Res. Lett., 46, 10 882-10 890, https://doi.org/10.1029/2019GL084088.

Zhang, X., and J. A. Church, 2012: Sea level trends, interannual and decadal variability in the Pacific Ocean. Geophys. Res. Lett., 39, L21701, https://doi.org/10.1029/2012GL053240.

Zhao, J., Y. Li, F. Wang, F. Zhai, and X. Yu, 2012: Spatialtemporal patterns and driving mechanisms of semiannual variations in the Philippine Sea. Deep-Sea Res. I, 68, 105-115, https://doi.org/10.1016/j.dsr.2012.07.001.

$\longrightarrow,-$, and _ 2013: Dynamical responses of the west Pacific North Equatorial Countercurrent (NECC) system to El Niño events. J. Geophys. Res. Oceans, 118, 2828-2844, https:// doi.org/10.1002/jgrc.20196. 